\title{
EDUCACIÓN Y FORMACIÓN, SABER PRÁCTICO Y SABER ERUDITO EN LOS MONASTERIOS FEMENINOS EN LA BAJA EDAD MEDIA ${ }^{1}$
}

\author{
EDUCATION AND TRAINING, PRACTICAL AND SCHOLARLY \\ KNOWLEDGE IN LATE MEDIEVAL FEMALE CONVENTS
}

\author{
EvA SCHLOTHEUBER \\ Institut für Geschichtswissenschaften (Düsseldorf)
}

\begin{abstract}
Resumen: Los monasterios femeninos medievales constituyeron, ya desde que vieron la luz en los comienzos del cristianismo, un espacio de vida singular. Gracias a los conocimientos de latín, necesarios para poder llevar a cabo las tareas litúrgicas, las religiosas tuvieron acceso a la tradición culta del Medievo europeo. Dado que las mujeres no eran admitidas en las instituciones educativas públicas, tales como escuelas de latín y universidades, las propias monjas asumieron el papel de educar y formar a las nuevas generaciones de religiosas. Sin embargo, los diversos campos de conocimiento de los conventos femeninos no se limitaban a los conocimientos teológicos, litúrgicos y literarios, sino que abarcaban también amplios saberes de tipo administrativo y jurídico. Estos saberes (como saberes ligados a la escritura) estaban adaptados a las exigencias particulares de la administración, desde la clausura, de la familia monástica y de la economía del convento. Podemos encontrar manifestaciones de los mencionados ámbitos de conocimiento en la estructura de las bibliotecas monásticas, pero también en la documentación administrativa de sus archivos.
\end{abstract}

\begin{abstract}
Women's monastic foundations, since their appearance in the early days of Christianity, constituted a particular type of space for living and learning. Religious women had to have sufficient command of Latin to carry out their liturgical duties; at the same time, their knowledge of Latin allowed them access to the scholarly traditions of the European Middle Ages. Since these women were excluded from public educational institutions, such as the Latin schools or the universities, as a rule nuns themselves assumed responsibility for educating the next generation of religious women. The various fields of knowledge taught in female foundations encompassed not only the theological, liturgical and literary, but also a sophisticated knowledge of administration and law that (in written form) was tailored towards the particular circumstances of managing, from within their monastic enclosure, the convent familia, its lands and economy. These fields of knowledge are reflected not only in the composition of their libraries but also in the written material pertaining to administration that is still preserved in monastic archives.
\end{abstract}

1 Abreviaturas utilizadas: BNM = Bayrisches National Museum (Museo Nacional Bávaro); BHSA = Bayerisches Hauptstaatsarchiv (Archivo del Estado de Baviera); BSBM = Bayerische Staatsbibliothek München (Biblioteca Estatal de Baviera); DFG = Deutsche Forschungsgemeinschaft (Fundación Alemana de Investigación); Clm = Codex latinus Monacensis; Ms. = Manuskript (manuscrito); KL = Klosterliteraria (Archivo monástico); SAD = Staatsarchiv Detmold (Archivo de Estado, Detmold).

Traducción del alemán por Natalia Juan Antón y Sonia López Sánchez. 
Palabras clave: monasterios femeninos en la Baja Edad Media; formación intelectual; bibliotecas; 'paisaje monástico femenino'; experiencia; conocimientos de latín.
Keywords: late-mediaeval women's monastic foundations; education; libraries; 'female monastic landscape'; knowledge based on experience; competence in Latin.

\section{SUMARIO}

1. Educación y formación: la instrucción en las escuelas monásticas.- 2. Experiencia: los conocimientos de las monjas a cargo de un oficio.- 3. Colecciones bibliográficas y bibliotecas monásticas.- 4. Resumen.- 5. Bibliografía citada.

Ego $K \mathrm{H}$ sedeo in cella sicut turtur in plateis unde hebbe dessen bref sulven dictert et spero, dat ik mik jeghen juw nicht konne vorscriven, gy weten wol wo latinsk ${ }^{2}$.

Con estas palabras se dirigía por escrito a finales del siglo XV una monja del monasterio benedictino de Lüne (cerca de Lüneburg al sur de Hamburgo) a su priora ausente, mencionando solo sus iniciales K.H. La monja benedictina de Lüneburg sabía leer y escribir y, tal como muestra la carta, también dominaba el latín, aunque probablemente considerara que su priora lo dominaba mucho mejor. Estas pocas frases ponen de manifiesto por sí solas un problema fundamental para la investigación de la educación y formación de las mujeres religiosas en la Baja Edad Media: por lo general, las monjas sabían escribir, pero el nivel de formación, incluso dentro de un mismo monasterio, podía variar notablemente. Esta observación es válida también en relación al desigual nivel de formación existente entre los diferentes monasterios femeninos o entre las ramas femeninas de las diferentes órdenes religiosas -Benedictinas y Cistercienses, Dominicas y Clarisas, Cartujas, Premostratenses y Canónigas de San Agustín, Brigidinas o Beguinas. No es posible realizar un estudio amplio y a la vez lo suficientemente detallado sobre la formación de las mujeres religiosas, pues el estado actual del análisis de las fuentes y de la investigación es muy desigual. Por ello en esta contribución se esbozarán tan solo algunos supuestos fundamentales, proponiendo ejemplos escogidos.

La educación y formación de las mujeres religiosas y, sobre todo, la formación erudita, es un tema al que apenas se le ha prestado atención en los Estudios Medievales. Aunque la función central de los monasterios del Medievo como centros religiosos, intelectuales y culturales ha suscitado siempre

\footnotetext{
2 "Yo, K.H., estoy sentada en esta celda como una paloma en la calle y he redactado esta carta yo misma, y espero no haber «cometido errores», pues sé que usted domina muy bien el latín”. Lüne, KL, Ms. 15, posición 7, f. 3r (foliación discontinua del manuscrito).
} 
un gran interés, en el caso de los monasterios femeninos se plantea el interrogante de hasta qué punto las mujeres que en ellos vivían, a menudo en estricta clausura, participaban en la vida espiritual e intelectual de su tiempo, o hasta qué punto podían contribuir activamente a la misma. Tenemos bastante información sobre la formación erudita de los monjes y clérigos seculares en las escuelas monásticas y catedralicias, pero poco sabemos sobre la formación, el horizonte intelectual y la participación en la vida religioso-literaria contemporánea de las monjas. Los escritos redactados por mujeres son una rareza en la Edad Media, puesto que la Iglesia oficial les prohibía opinar públicamente sobre cuestiones religiosas a menos que la autorización les llegase por revelación divina. Por eso, la investigación pasada ha clasificado a las mujeres religiosas principalmente como receptoras de literatura religiosa en lengua vernácula, y ha puesto en duda que en la Baja Edad Media estas dispusiesen de suficientes conocimientos de latín como para entender por sí mismas la Biblia o los escritos patrísticos ${ }^{3}$. Más bien parecían depender de la ayuda de los priores y confesores, sobre todo para descifrar el legado formal del latín. El interés por la historia y la cultura de los monasterios femeninos ha ido creciendo en los últimos años a nivel internacional ${ }^{4}$. Si bien solo a través de amplios estudios específicos podemos llegar a hacernos una imagen precisa acerca de la competencia lingüística de las monjas, gracias a las investigaciones recientes sabemos ya actualmente que en el Imperio Romano Germánico sobre todo las monjas de los monasterios femeninos del norte de Alemania disponían de una larga tradición en cuanto a formación erudita se refiere aunque, al contrario que sus colegas masculinos, lo mostrasen poco de cara al exterior. Sin embargo, factores fundamentales tales como la pertenencia a una determinada orden, su competencia lingüística y su formación, la tradición espiritual de cada convento, así como el entorno teológico, determinaron el horizonte intelectual y la específica expresión espiritual de cada una de las comunidades monásticas. En este sentido, los monasterios de diferentes regiones europeas fueron

\footnotetext{
${ }^{3}$ N. Henkel, N.F. Palmer (eds.), Latein und Volkssprache; F. Grubmüller, Geistliche Übersetzungsliteratur, pp. 59-74 y por último, en S. Mengis, Schreibende Frauen, en especial la introducción de N.F. Palmer, Vorwort, pp. 11-24. Han recalcado especialmente el peso del alemán en los conventos P. Ochsenbein, Latein und Deutsch, pp. 42-51 y B. Newman, The Visionary Texts, pp. 151-169.

4 H. Lähnemann, E. Andersen (eds.), A Companion; J. Mecham, Sacred Communities; F. Griffiths, J. Hotchin (eds.), Partners in Christ, Women; V. Blanton, V. O'Mara, P. Stoop (eds.), Nuns' Literacies; J.F. Hamburger, E. Schlotheuber, Books in Women's Hands. Véase también el proyecto europeo comparativo relativo a la historia del arte: Reassessing the Roles of Women as 'Makers' of Medieval Art and Architecture. CSIC. Centro de Ciencias Humanas y Sociales, Madrid; ya ha sido publicada una edición de dos tomos: T. Martin (ed.), Reassessing; J.F. Hamburger, Crown and Veil, ésta es una traducción del inglés de la obra: J. Frings (ed.), Krone und Schleier; E. Schlotheuber, I. Gardill, H. Flachenecker (eds.), Nonnen; N.F. Palmer, Daughters, pp. 85-100; J.F. Hamburger, Nuns as Artists.
} 
creando sus propias tradiciones. Así, por ejemplo, e independientemente de la orden a la que pertenecían, los monasterios femeninos del sur de Alemania y de Austria formaban parte de tradiciones y círculos literarios distintos de los del norte de Alemania o de los conventos neerlandeses o belgas ${ }^{5}$. Esto plantea la cuestión de cómo establecer una relación entre los resultados divergentes de las investigaciones respecto a la formación y al acceso a la literatura de los conventos femeninos. Se ha recurrido, como forma de acceso metodológico, al concepto "paisaje monástico" (Klosterlandschaft), sobre cuya definición e interpretación se ha discutido intensamente en los últimos años ${ }^{6}$, de forma que las distintas tradiciones y los diferentes desarrollos arriba mencionados se pudiesen estudiar con un enfoque similar. En 2012 Franz J. Felten compendió los diversos enfoques de investigación recogidos bajo este concepto ${ }^{7}$, centrándose metódicamente sobre todo en la crítica de Gert Melville, quien considera que el concepto de "paisaje monástico" es, en tanto que categoría analítica, demasiado amplio e indeterminado ${ }^{8}$. Felten llega a la conclusión de que si bien el concepto de "paisaje monástico" abarca numerosas connotaciones que imposibilitan una definición clara del mismo, su uso pragmático como concepto de investigación, como concepto de orden y análisis heurístico, resulta, sin embargo, absolutamente fructífero, ya que admite una percepción comparativa. De todas formas debe tenerse en cuenta que cada paisaje monástico no se da históricamente, sino que se configura según el enfoque y el objeto de estudio ${ }^{9}$. La forma más adecuada de definir un paisaje monástico en este contexto probablemente sea partir de los centros que lo formaban ${ }^{10}$. Esto se corresponde bien con las condiciones del mundo medieval en tanto que el espacio geográfico estaba constituido y dominado por sus centros, es decir, por castillos y residencias, por conventos y colegiatas, por ciudades y lugares centrales. Aunque monjes o monjas, vasallos o siervos, príncipes, princesas o

\footnotetext{
5 Véanse los talleres sobre el intento de agrupar los paisajes monásticos en un enfoque comparativo realizados en cooperación entre la Universidad de Gotinga (cátedra del Prof. Hedwig Röckelein) y la Central European University, Budapest: Monastic Landscapes - Physical and Spiritual. International, interdisciplinary workshop. Marzo 5-7, 2009, Budapest; Medieval Monastic Regions in Central Europe - The Spiritual and Physical Landscape Setting of Monastic Orders and Religious Houses, 2010, Gotinga. Así como H. Röckelein, Bairische, sächsische und mainfränkische Klostergründungen, pp. 23-55. Para la región del Bajo Rin, fuertemente marcada en el siglo XV por la Devotio Moderna, ver actualmente M. Costard, Spätmittelalterliche Frauenfrömmigkeit; R. Schieffer, Die Entstehung, pp. 7-28; G. Melville, A. Müller (eds.), Female vita religiosa.

${ }^{6}$ R. Czaja, H.-D. Heimann, M. Wemhoff (eds.), Klosterlandschaften.

${ }^{7}$ F. Felten, Klosterlandschaften, pp. 157-189.

${ }^{8}$ G. Melville, Klosterlandschaft, pp. 195-222.

${ }^{9}$ F. Felten, Klosterlandschaften, p. 189.

${ }^{10}$ P. Carmassi, E. Schlotheuber, A. Breitenbach (eds.), Schriftkultur, pp. 7-17.
} 
dignatarios eclesiásticos estuviesen integrados según clase y sexo en diferentes sistemas de referencia o redes sociales, cada región se desarrollaba como una área cultural específica a partir de la aglutinación competitiva de sus residencias o casas. Por su parte, estos centros religiosos, económicos y sociales estaban marcados por su historia y sus relaciones de poder, por el idioma, por sus tradiciones religiosas y literarias, por sus leyes y por sus costumbres. Aquí tomaremos en consideración especialmente el paisaje monástico del norte de Alemania de finales de la Edad Media, aun si comparándolo con el sur. Estos monasterios transmitían sus tradiciones, portadoras de identidad, con todos los medios posibles: a través de textos e imágenes, oraciones, canto y poesía, y también mediante las redes sociales que unían las cortes laicas con las espirituales. Los monasterios femeninos jugaban asimismo un rol determinante en estos centros, pues tras las fundaciones eclesiásticas medievales no solo estaban las diferentes familias fundadoras, sino también los círculos sociales ligados a ellas -los frunde-, cuyos parientes vivían juntos en el monasterio, se casaban entre sí y con frecuencia celebraban esta solemnidad en el monasterio y cuidaban de los sepulcros familiares. Esto conllevaba que los monasterios, al igual que los señoríos o el patriciado urbano, formasen parte de una red de uniones y obligaciones sociales que finalmente también determinaba sus deberes religiosos y sus intereses literarios, su círculo social y por ende, su campo de actuación ${ }^{11}$. Así, las diferencias que encontramos tanto en el nivel de formación de las monjas como en la estructura de sus bibliotecas derivan en parte de la Orden a la que pertenecían, pero en gran medida también de tales relaciones sociales.

Uno de los motivos por los que las investigaciones sobre la formación de las mujeres religiosas en el Medievo ha suscitado tan poca atención durante tanto tiempo, aun disponiendo de numerosos testimonios eruditos y contando con una intensa producción de manuscritos, reside en el hecho de que las fuentes a menudo nos muestran un ideal de vida religiosa femenina en el que una monja consagra su vida a la oración y a la contemplación en rigurosa clausura. Según esta auto-imagen y hetero-imagen de las monjas que se identifica por la cercanía espiritual a Dios y no por la formación teológica, quedaba poco margen para la formación culta o para surtir sus bibliotecas extensamente con contenidos orientados, como sucedía en los monasterios masculinos, según el currículo universitario, las siete artes liberales, la

${ }^{11}$ Véase C. Kleinjung, Frauenklöster als Kommunikationszentren para el concepto de monasterios de mujeres como centros de comunicación.Véase también K.U. Mersch, Soziale Dimensionen visueller Kommunikation. 
filosofía y la teología ${ }^{12}$. La idea de una vida de clausura que no exigía requisitos intelectuales especiales, marcada por la castidad, la contemplación y la oración, justificaba la respetada posición religiosa y social de las monjas como mediadoras entre Dios y la Tierra. Por su especial cercanía espiritual a Dios también se las conocía como las esposas del más alto Rey, como esposas de Cristo (sponsa Christi) ${ }^{13}$. Por ello, el libro que a menudo aparece retratado en las manos de las mujeres religiosas en las imágenes de los retablos o lápidas sepulcrales medievales, no simbolizaría tanto el conocimiento teológico o la competencia lingüística, sino la contemplación y cercanía espiritual a Dios. Esta auto-imagen y hetero-imagen también estaba condicionada por la posición que la Iglesia del Medievo asignaba a las mujeres espirituales. Las propias monjas construyeron una imagen de sí mismas en la que para la vida espiritual no era necesario tener conocimientos intelectuales. Esta autodescripción se ha mostrado tan poderosa que ha marcado la pauta de la propia investigación. Así, la cuestión de la formación erudita de la monjas pasó a ser desatendida. Pero la oración y la contemplación eran solo una parte de la historia y las mujeres eran perfectamente conscientes de ello, pues la vida diaria que llevaban en el convento era tan exigente que era necesario contar con una profunda formación erudita. Fundamentalmente podemos distinguir tres áreas en las que eran necesarios conocimientos específicos y una formación erudita en los monasterios femeninos. En primer lugar, el conocimiento litúrgico y teológico, estrechamente ligado a tareas particulares de oración para las que se debía saber leer, escribir y tener al menos conocimientos pasivos de latín; a su vez, esta transmisión de conocimientos en los monasterios femeninos estaba estrechamente relacionada con la interpretación de la liturgia -por lo tanto, se puede hablar de una tradición del conocimiento propia y vinculada a las tareas específicas de las mujeres religiosas ${ }^{14}$. En segundo lugar, en los conventos se transmitían conocimientos específicos, esto es, destrezas "prácticas" tales como iluminar manuscritos, producir colores y copiar libros, pero también hacer labores textiles, teñir y tejer alfombras. Estas destrezas manuales, sobre las que no entraremos en detalle, se transmitían de generación en generación y eran, por lo tanto, específicas de cada convento de forma que cada comunidad las fue desarrollando y finalmente llegó a ser famosa por ellas. En tercer lugar debemos destacar un área que hasta ahora apenas ha sido tratada en los estu-

\footnotetext{
${ }^{12}$ Véase por último respecto a los franciscanos: B. Roest, A History; A. Derolez, Les Catalogues; J. Duft, Bibliothekskataloge vol. I, pp. 192-202.

13 Véase E. Schlotheuber, Klostereintritt, pp. 104-129.

${ }_{14}$ Apuntan a ello resultados de investigaciones actuales, J. Thali, Qui vult cum Deo semper esse, pp. 421-458; T. Mattern, Liturgie im Text, pp. 217-239; J.F. Hamburger, E. Schlotheuber, Books in Women's Hands.
} 
dios medievales: se trata del conocimiento adquirido a partir de la experiencia, necesario sobre todo para gobernar el monasterio y dirigir su poderosa economía. En el siglo XV las mujeres religiosas dejaron constancia de este tipo de conocimiento en múltiples escritos en forma de los así llamados Hausbücher o de libros de cuentas.

\section{EDUCACIÓN Y FORMACIÓN: LA INSTRUCCIÓN EN LAS ESCUELAS MONÁSTICAS}

En la segunda mitad del siglo XIII, el sacerdote Humberto de Romans, maestro general de la Orden de los Dominicos, se involucró en la formación de los miembros femeninos de su orden. En su escrito De eruditione determina que no se deberían proporcionar conocimientos exhaustivos de las bases teológicas y dogmáticas a las mujeres, tal y como sí es necesario en el ministerio de la predicación. Para ello se podían alegar cuatro razones: la falta de aptitudes intelectuales de la mujer (defectus sensus), su posición de subordinación bajo la dirección de los hermanos predicadores (conditio subiectionis), el hecho de que una mujer predicadora incita al desenfreno (ad luxuriam) y en memoria a la estupidez de la primera mujer (in memoriam stultitiae primae mulieris), es decir, el desacierto de Eva, que tantas consecuencias tuvo ${ }^{15}$. Esta definición negativa y excluyente sobre la formación teórica de las mujeres religiosas se correspondía con la postura tradicional de la Iglesia en relación a esta cuestión ${ }^{16}$. Pero durante un discurso a las hermanas, el general de la orden también mencionó de forma positiva las capacidades intelectuales y la forma de instrucción requeridas. Muchas de las comunidades femeninas tenían a su lado guías poco comprometidos e incultos, en cambio ellas -las Dominicascontaban con responsables selectos, eruditos y especialmente instruidos para tal tarea, que formaban a las mujeres predicando de continuo, mostrando un compromiso especial a la hora de asesorarlas espiritualmente, visitándolas re-

\footnotetext{
15 "Circa personam est notandum, quod debet esse sexus virilis (...) Huius autem ratio est quadruplex. Prima est defectus sensui, de quo non praesumitur in muliere tantum sicut in viro. Secunda est, conditio subiectionis, quae inflicta est ei: Praedicator autem tenet locum excellentem. Tertia est, quia si praedicat, aspectu suo provocaret ad luxuriam, sicut dixit Glossa hic. Quarta in memoriam stultitiae primae mulieris" (H. de Romans, De eruditione Praedicatorum, p. 435). Véase la edición de J.J. Berthier (ed.), Humbert von Romans, pp. 373-484; y también S. Lusignan, Humbert de Romans, pp. 201-209. Para una discusión en profundidad sobre las fuentes normativas dominicanas concerniente a la educación de las monjas, véase: J. Hamburger, E. Scholotheuber, S. Marti, M. Fassler (eds.), Liturgical Life and Latin Learning.

${ }^{16}$ Con respecto al lugar de la mujer en la Iglesia, véanse las obras L. Müller (ed.), Der Empfänger, pp. 111-113; A. Angenendt, Geschichte der Religiosität, p. 266.
} 
gularmente, y tomándoles la confesión con más frecuencia de lo habitual ${ }^{17}$. Las declaraciones del general de la orden dejan claro que los clérigos asesores eran decisivos para el acceso a la formación de las monjas, aunque por supuesto también ejercían una función de control sobre ellas ${ }^{18}$. En el caso de la orden dominica esto significaba que la instrucción a manos de los hermanos predicadores debía garantizar la comprensión ortodoxa de los contenidos de la $\mathrm{Fe}$, que sus visitas fuesen conformes a las reglas del mundo espiritual y que la confesión asegurase la dedicación espiritual a Dios ${ }^{19}$. El marco específico de la formación abarcaba, por lo tanto, el estudio de algunos temas teológicos y dogmas eclesiásticos, y esto suponía literatura teológica traducida en el caso de las hermanas del sur de Alemania ${ }^{20}$. La postura resaltada por Humberto de Romans, según la cual las mujeres no necesitaban una formación teológica específica, era básicamente compartida por las demás órdenes. Acorde a esta postura, que dejaba la instrucción profunda de las monjas en manos de los monasterios masculinos, apenas se hace mención de la formación de las hermanas en las reglas de la orden o en los estatutos. Generalmente solo se alude a las prácticas de humildad, pobreza y obediencia, a moldearse a los mores, a la destreza en los trabajos manuales y a los conocimientos acerca del desarrollo litúrgico del año eclesiástico. Las Constituciones de San Sixto más antiguas (1228-1236) determinan claramente cuál será la línea básica a seguir por la orden dominica en el porvenir: las niñas deberán aprender a leer y escribir para que puedan ejercitar el officium divinum, sin embargo, no será necesario que estudien la gramática (grammaticalia vero et auctores discere non oportet) ${ }^{21}$. Estos "requisitos mínimos" exigidos por las reglas y estatutos suelen tomarse como argumento para poner en duda una profunda formación culta de las mujeres.

Sin embargo, estos conjuntos de normas ratificaban sobre todo que a las mujeres no les estaba permitido el acceso al currículo de la orden o a

\footnotetext{
17 "Notandum autem, quod circa filias maior solet adhiberi custodia quam circa filios. (...) Item sunt multi [!] qui habent rectores insufficientes in sensu et scientia, istis vero non traduntur fratres curam earum habentes nisi valde sufficientes et electi. Item sunt multae quae raro visitantur et instruuntur a suis rectoribus, etsi sint bene sufficientes. Istis vero frequenter praedicat et frequenter audiuntur earum confessiones et conferuntur consolationes multae spirituales" H. de Romans, De Eruditione Praedicatorum, lib. II, De modo prompte cudendi, Sermo 48, pp. 191-193, aquí p. 192. Véase también C. Carozzi, Humbert de Romans, pp. 249-261.

18 Véase F. Griffiths, J. Hotchin (eds.), Partners in Christ.

19 M.-L. Ehrenschwendtner, Die Bildung.

${ }^{20}$ Sobre los diferentes aspectos en la enseñanza véase A.B. Mulder-Bakker (ed.), Seeing and Knowing, pp. 9-16.

21 "Iuniores discant legere et cantare, ut divinum officium valeant exercere; grammaticalia vero et auctores discere non oportet. (...) Sorores que vigintiquatuor annos transcenderunt, si nesciunt psalterium, do novo non discant" en A. Simon, L'Ordre des Pénitentes, anexo II, pp. 142-169, y aquí véase capítulo XXI De labore, p. 165.
} 
otras posibilidades de formación en las escuelas catedralicias de la misma. Pero las mujeres supieron sacar partido de este marco, estrictamente receptivo y definido en función del Derecho Canónico, y ampliarlo creativamente ${ }^{22}$. En especial la mística les ofrecía espacios de libertad particulares en los que desarrollaron caminos significativos de espiritualidad femenina y que, como ya se ha comentado, estaban ligados sobre todo a la interpretación litúrgica. Tal y como era costumbre en la Edad Media, la interpretación de las reglas formaba únicamente el marco general. Para su desarrollo concreto, también jugaba un papel importante el ideal regional y el momento, es decir, la idea general sobre cuáles debían ser, según sus coetáneos, los conocimientos adecuados para las monjas y hermanas. En periodos de reformas, los requisitos generales de formación eran claramente más exigentes. La gran Reforma de la Iglesia, que está vinculada con los Concilios de Constanza (1414-1417) y Basilea (1431-1449) durante el Imperio Romano Germánico y que más tarde fue implantada con gran esfuerzo en los monasterios, exigía sobre todo a los conventos femeninos, además del seguimiento de las reglas (observancia), el cumplimiento riguroso de la clausura y el restablecimiento de la vida comunitaria $^{23}$. Pero la implantación de la Reforma también impulsó la formación intelectual y conllevó el desarrollo de las bibliotecas, pues si la vida exterior permanecía cerrada, la interior debía abrirse ${ }^{24}$. Por ello, se ha demostrado que en muchos conventos las mujeres poseían un mejor conocimiento del latín de lo que se puede suponer a partir de las fuentes normativas. En las disposiciones sobre el noviciado encontramos generalmente noticias sobre la formación elemental de los aprendices. En realidad, el noviciado no era el momento para la adquisición de conocimientos, sino un periodo de exploración en el que se determinaba si se quería seguir el camino religioso. Por ello Humberto de Romans recalca a los conventos masculinos que los recién llegados debían ser conscientes del arduo camino que les esperaba y que no debían permitir que las difíciles cuestiones teológicas les apartasen de las tareas verdaderas ${ }^{25}$. Así, mientras que la formación elemental se debía recibir antes de iniciar el

${ }^{22}$ J.F. Hamburger (ed.), Leaves from Paradise; J.F. Hamburger, E. Schlotheuber, Books in Women's Hands.

${ }^{23}$ A. Ranft, M. Meumann (eds.), Altes Herkommen; K. Elm (ed.), Reformbemühungen.

${ }^{24}$ H. Smolinsky, Kirchenreform, pp. 35-51; D. Mertens, Monastische Reformbewegungen, pp. 157-181; W. Williams-Krapp, Frauenmystik, pp. 159-172; W. Williams-Krapp, Observanzbewegungen, pp. 173-188.

25 "Non enim novitius volens proficere in religione debet studere in altis questionibus aut obscuris mysteriis sicut docet beatus Bernardus, sed in vitis patrum et sanctorum et huiusmodi planis et facilibus doctrinis et hoc est lac concupiscere sanctam doctrinam parvulis congruentem. Aliud est cuiusmodi profectus est desiderandus. Non enim profectus in laude vel honore vel alia quacunque re mundiali est appetendus" (H. de Romans, De Eruditione Praedicatorum, lib II, De modo prompte cudendi, Sermo 7, pp. 117-121, aquí p. 119). 
noviciado, la formación propia de la orden en los conventos masculinos no empezaba hasta haber hechos los votos, una vez que la decisión de seguir la vida religiosa ya estaba tomada y los votos profesados ${ }^{26}$. En los conventos femeninos la situación era algo diferente. Puesto que muchas veces las niñas entraban en el convento a la edad de cinco o seis años, el "noviciado" solía designar de manera general el tiempo transcurrido hasta la profesión. En este tiempo la niñas estaban bajo la tutela de una magistra que las instruía en las obligaciones litúrgicas y otras tareas, pero que también les enseñaba a leer y escribir y, en mayor o menor medida, latín. En el libro de profesiones de Johannes Meyer (1422-1484), Liber officiorum sororum ordinis predicatorum, una traducción libre y ampliada del Liber de instructione officialium de Humberto de Romans ${ }^{27}$, adaptada a los conventos femeninos, se designa como tutora de las educandas (hasta los veintidós años) a una magistra (junge meistrin) ${ }^{28}$. Una escuela de novicias (novitzen schul) debía estar situada en un lugar tranquilo, alejado de la actividad diaria de la vida del convento. En ella, las educandas debían ser instruidas en el canto y la lectura (in singen und in lesen) y aprender de memoria partes importantes de la liturgia: el Réquiem, el Pequeño oficio de Nuestra Señora, las Vísperas, la Liturgia de las Horas y similares (die ding, die si uswendig sond lernen, als $d z$ amt der totten, die zitt von unser lieben frowen, die teglichen vesperpsalmen und der gemeinen ziten und des gelichen) ${ }^{29}$. La maestra debía mantener "a raya" a las niñas (in aller geistlicher züht), es decir, disciplinarlas para la vida diaria regulada en el convento, controlar su comportamiento en el coro, en el refectorio y en la lectura del capítulo. Solo cuando dominaran estas tareas, podían aprender otras cosas, como por ejemplo a copiar libros. Aquellas hermanas que mostraban aptitud y capacidad para el estudio eran instruidas en las artes liberales (freyen künsten), generalmente en la künst grammattick ${ }^{30}$ por dos hermanas seleccionadas cuidadosamente por la priora. Pero el estudio no debía impedir que desatendiesen sus obligaciones generales ni desfavoreciesen "las obras del amor o de la orden" (die werck der mynn oder des ordens). Por lo tanto el marco general quedaba fijado en los términos de Humberto de Romans, pero permitía a los conventos cierta libertad, de forma que algunos miembros del convento podían profundizar en los conocimientos del latín y de la formación erudita. Ya las disposiciones normativas preveían un nivel de conocimiento

${ }^{26}$ Para los franciscanos, véase B. Roest, A History, pp. 237-245.

27 H. de Romans, Liber de instructione officialium, vol. IV, pp. 150-197.

${ }^{28}$ El libro de profesiones de Johannes Meyer solo está publicado por fragmentos en J. König (ed.), Die Chronik, Beilage 1: Die Schriften des Johannes Meyer, p. 201.

${ }^{29}$ Ibidem.

${ }^{30}$ B. Hasebrink, Tischlesung, p. 195. 
diferente, adaptado a las inclinaciones y al talento de las hermanas, así como la formación propia del convento estaba, en general, dirigida a las necesidades de la comunidad. A pesar de las referencias parcialmente contradictorias que aparecen en las fuentes, no debe infravalorarse la capacidad intelectual de las mujeres de los conventos en la Baja Edad Media. Algunas de las mujeres religiosas del siglo XV gozaron de tan buena reputación en los círculos humanistas que el erudito benedictino Johannes Butzbach (Piemontanus) se vio obligado a compilar las vidas de estas, al igual que la de hombres sobresalientes, en una obra dedicada a ellas: De illustribus seu studiosis doctisque mulieribus ad Aleidem, sanctimonialem virginem in Insula Rolandi ${ }^{31}$.

Pero, ¿cómo nos podemos imaginar en concreto la situación de la formación en los conventos femeninos en la Baja Edad Media? La formación de las futuras monjas constituía una parte importante de la vida en el convento, pues a través de ella se encauzaban la actitud y las dotes de la próxima generación. Aquí era por donde había que comenzar si, por ejemplo, la disposición interior de las monjas hacia la vida religiosa debía ser modificada y si las futuras miembros del convento debían ser disciplinadas según los mandatos de la Reforma. Dado que la educación monástica estaba dirigida completamente a las tareas litúrgicas y espirituales de las monjas de coro, la instrucción de niñas laicas en el convento no estaba en absoluto prevista. El estrecho lazo entre las futuras monjas y las muchachas que más tarde abandonarían el convento dificultaba el proceso de disciplinar a las educandas del convento $\mathrm{y}$, en concreto, el cumplimiento de la clausura rigurosa ${ }^{32}$. Aun así, las fuentes revelan una y otra vez que las niñas laicas eran entregadas a los conventos con el único fin de ser educadas. El motivo por el que también las hijas que más adelante debían contraer matrimonio eran enviadas a los conventos para su educación y formación era que, a falta de alternativas institucionales, por regla general, las familias veían en la enseñanza de los conventos una formación digna para sus hijas. Nikolaus von Siegen (†1495), monje del monasterio Peterskloster de Erfurt y defensor incondicional de la reforma monástica, sabía que los padres de estas muchachas valoraban especialmente los conocimientos de la lengua latina y los disciplinatos mores, es decir, la capacidad de autodominio, y estaban más que dispuestos a pagar por esta formación ${ }^{33}$. No obstante, la postura de las órdenes y de las fuerzas reformistas respecto a esta cuestión estaba bien definida: en general, prohibían instruir a niñas laicas en el monasterio. En el caso de que un convento hubiese admitido a niñas laicas

31 H. Fertig (ed.), Neues aus dem Literarischen Nachlasse, pp. 40-57. Véase también G. Signori, Berïhmte Frauen, pp. 27-44.

${ }^{32}$ E. Schlotheuber, Klostereintritt, pp. 111-120.

33 Ibidem, pp. 113-115.

ANUARIO De Estudios Medievales, 44/1, enero-junio 2014, pp. 309-348 ISSN 0066-5061, doi:10.3989/aem.2014.44.1.10 
en las clases, en el momento en que se implantase una reforma, eran estas las que debían abandonar en primer lugar el convento. Sin embargo, a menudo las familias fundadoras o los benefactores monásticos más influyentes presionaban a los conventos para que accedieran a admitir a sus hijas para educarlas y disciplinarlas, muchas veces a cambio de una buena remuneración. No se debe subestimar la presión ejercida sobre las comunidades religiosas para que accedieran a esta pretensión. Sobre todo en tiempos de escasez, beneficios de este tipo eran muy tentadores para las comunidades. Cuán severa había de ser la resolución de esta cuestión dependía, por un lado, de las reglas y su cumplimiento, pero, por otro, también de la situación económica, la cual podía llegar a limitar de manera determinante el campo de actuación de un convento frente a su entorno directo.

El periodo de aprendizaje de las monjas, con una media de cinco a seis años, era más bien largo, y suponía un esfuerzo considerable para la congregación. Independientemente de la edad, las novicias comenzaban su formación en la escuela monástica por regla general un año después de su admisión en el convento. Magdalena Schneverding llegó en 1515 con siete años al monasterio benedictino de Lüne y un año más tarde fue admitida en la escuela monástica, en la que finalmente estuvo siete años ${ }^{34}$. Su salida de la escuela monástica en el año 1523 fue celebrada solemnemente en presencia de todo el convento y del prior. De las redacciones en latín de la colegiala monástica de Ebstorf se concluye que la abadesa, antes de que las candidatas profesasen los votos monásticos, examinaba personalmente los dictamina de las mismas $^{35}$. Cuando Magdalena Schneverding profesó sus votos monásticos en 1525, llevaba viviendo en Lüne ya diez años, al igual que Anna von Bülow quien finalizó la escuela monástica en cinco años. A pesar de que los estatutos disponían que las clases escolares se finalizasen antes de profesar los votos monásticos, en Lüne se le daba tal importancia a la instrucción, que en 1507 se permitió que tres hermanas profesasen sus votos y siguieran durante un año más las clases. A más tardar con la implantación de la Reforma en el siglo XV, la capacidad de dominar el latín contribuiría a la buena reputación de estos conventos de monjas. Y las mujeres otorgaban gran valor a la buena reputación de sus instituciones. Respecto a esto, no solo la comunicación entre los conventos, sino también la latente situación de competitividad por ganarse fundaciones eclesiásticas y por mantener buenas relaciones con las familias influyentes, podían actuar como estímulo. La lengua culta usada en la vida diaria del convento aumentaba la distancia hacia los propios familiares

34 Ibidem, pp. 121-137.

35 E. Schlotheuber, Ebstorf und seine Schülerinnen, pp. 169-221. 
y repercutía, por lo tanto, directamente en la autognosis. El uso de esta lengua exclusiva reforzaba a las monjas de coro como grupo particular con tareas propias y específicas, lo cual hacía que las monjas sobresaliesen dentro de la propia comunidad monástica, destacándolas de sus hermanas legas y de los curas.

Al contrario que en el caso de los monasterios masculinos, a los conventos femeninos apenas se incorporaban personas adultas y ya formadas que durante o tras finalizar sus estudios decidieran seguir una vida religiosa. Las futuras miembros del convento eran admitidas por lo general en la niñez o adolescencia, de forma que para las monjas surgía con el tiempo un problema grave y probablemente de larga duración: el nivel de educación en un convento femenino dependía, en principio, del nivel de formación de la magistra, de modo que podía darse el caso de que la facultad para entender y escribir latín en medida suficiente disminuyese de generación en generación. En el convento cisterciense de Lichtental, cerca de Baden-Baden, se dio un caso así; la competencia lingüística fue decreciendo hasta tal punto que los conocimientos de latín necesarios para la vida cotidiana del convento ya no fueron suficientes para entender los textos litúrgicos, las reglas monásticas adaptadas a las monjas o las lecturas en el refectorio. La hermana Regula, una cisterciense que llegó a Lichtental durante la Reforma, desplegó, una vez finalizada la Reforma a mediados del siglo XV, una intensa actividad de traducción y copia de libros. Con ello quiso poner al alcance de sus compañeras de convento, desconocedoras del latín, al menos las obras necesarias para las lecturas diarias en el refectorio ${ }^{36}$. Pero, evidentemente, muchas de las comunidades femeninas del norte de Alemania no eligieron el camino de la actividad traductora. Al contrario, en la segunda mitad del siglo XV, se decantaron por un camino probablemente más dificultoso, dedicándose de nuevo y con más ardor al estudio del latín. Johannes Busch, canónigo de Windesheim y visitador de los conventos femeninos del norte de Alemania, confirma los buenos conocimientos de latín de varios conventos de monjas. En especial, elogia a las alumnas de la colegiata de canónigas agustinas Marienberg en Helmstedt, cuyos conocimientos de latín pudo comprobar personalmente:

La hermana Tecla, que poseía muy buenos conocimientos de gramática latina, instruía junto con la subpriora a las jóvenes y a las monjas en canto y en ciencias escolásticas. Estas aprendían tan rápidamente que podían entender e interpretar sin dificultades las

${ }^{36}$ G. Stamm, Klosterreform, pp. 63-71, en especial pp. 67-68; P. Schindele, Der Beitrag der Lectio Divina, pp. 13-16.

ANUARIO DE Estudios MEdiEvales, 44/1, enero-junio 2014, pp. 309-348 ISSN 0066-5061, doi:10.3989/aem.2014.44.1.10 
Sagradas Escrituras y redactar con maestría epístolas o mensajes, como he podido comprobar con mis propios ojos y como se puede ver en las cartas que siguen a continuación ${ }^{37}$.

La magistra Tecla había sido llamada a Marienberg durante la Reforma expresamente para instruir a las educandas. Este intercambio de maestras era el camino predilecto y más usual, y fue iniciado conscientemente por los reformadores de los conventos. Durante el capítulo en Erfurt de 1463 los padres benedictinos de la Congregación de Bursfelde dispusieron que las monjas y las novicias debían hablar en latín en vez de en alemán durante las clases, tanto entre ellas como con los patres. Y además, en caso de que esto no se respetase, se las debía castigar como a los fractores silencii ${ }^{38}$. Ya que, conforme a la voluntad de los reformadores de Bursfelde, el latín debía convertirse en la lengua de comunicación como lo era en los monasterios masculinos, todas las mujeres del convento debían contar con la posibilidad de poder entender y hablar el latín. Para ello, los benedictinos de Bursfelde decidieron que las principiantes (rudes) o aquellas que poseían menos nociones de latín (minus instructe) podían decir en alemán lo que no sabían expresar en latín, anticipando la expresión cum Iesulicencia para luego volver a repetirlo en latín. Este procedimiento coincidía con el que se seguía en las escuelas de latín. Todo esto demuestra que los benedictinos de la Congregación Reformadora de Bursfelde valoraban que las monjas tuviesen suficientes conocimientos de latín, hasta tal punto que, en el caso de que no hubiese monjas lo suficientemente formadas, incluso recomendaban encomendar esta labor a un maestro de latín.

Con la intensificación de las clases de latín, también cambió el modo de transmisión de esta lengua. La antigua costumbre de asimilación sintética que solía practicarse en las escuelas monásticas y que consistía en la memorización de partes completas del idioma, se complementó con la comprensión analítica de la estructura oracional latina. En la biblioteca del monasterio benedictino de Ebtstorf se encontraba una asombrosa cantidad de gramáticas latinas y de textos para la práctica del latín provenientes de la segunda mitad del siglo XV -cantidad que viene justificada por el hecho de que las clases se

${ }^{37}$ K. Grube (ed.), Johannes Busch, Liber de reformatione, p. 621: "Soror Tecla in grammatica competenter docta iuvenes instruxit puellas et moniales in cantu, in scientiis scholasticalibus una cum suppriorissa, que in tantum in eis profecerunt, ut scripturas divinas clare intelligerent, exponere scirent et literas sive missivas in bono latino magistraliter dictarent, sicut ad oculum ipse vidi et examinavi, ut in epistolis subsequentibus aperte ostenditur". Véanse las misivas de las alumnas de la escuela monástica a la exmaestra Tecla (ibidem, p. 618-627). Próximamente se publicará la nueva edición de B. Lesser (ed.), Johannes Busch, Liber de reformatione monasteriorum.

${ }^{38}$ E. Schlotheuber, Klostereintritt, p. 276. 
orientaban a un aprendizaje profundo de la gramática. Durante las lecturas en voz alta que se hacían en el refectorio, varias veces una monja de Ebstorf -cuyo nombre no se da a conocer- habla sobre esta nueva forma de enseñanza:

Así que nos conviene esforzarnos por lograr una sólida base [de conocimientos] y pugnar con todas nuestras fuerzas por conocer las reglas gramaticales para que la joya dorada de la sabiduría no se pierda, a pesar de que sea insuficiente, en este lugar muy digno de respeto a causa de nuestro descuido y pereza; pero vamos a esmerarnos con todas nuestras fuerzas para que día a día aumente. Pues si hubiésemos perdido oro y plata, se trataría de una pérdida que podríamos enmendar; pero si se pierden los fundamentos de la sabiduría, se ocasionaría un perjuicio irrevocable para la religiosidad. En el momento en el que los conocimientos de la sabiduría se extingan, también se verán destruidos, con toda seguridad, los frutos de la vida religiosa. Por este motivo, nuestra magistra se ha esforzado continuamente en aleccionarnos en todas las estructuras oracionales para que podamos entender las Sagradas Escrituras, pues leer y no entender significa olvidar ${ }^{39}$.

La eficacia de la oración, es decir, su función más elevada, se vincula aquí con la competencia lingüística, recibiendo por lo tanto un alto valor propedéutico para las pupilas. La monja de Ebstorf acentúa reiteradamente la importancia de las estructuras oracionales del latín, que acaban destacando como el elemento nuevo y más notable de la enseñanza. Esta monja anónima favoreció así seguramente una nueva forma de aprender la lengua. Podemos concluir aquí, por tanto, que probablemente la Reforma produjo un cambio destacado en la enseñanza de lenguas. Sin embargo, la meta de la enseñanza no era solo aprender a leer y a recitar textos correctamente en latín (recte legendi), sino también trabajar la correcta comprensión e interpretación teológica de los mismos (recte intelligendi):

Por ello, en la flor de nuestras vidas, no vamos a estancarnos a causa del vicio de la pereza, sino que vamos a dedicarnos con todas nuestras fuerzas al estudio de la gramática hasta que hayamos adquirido la capacidad de leer correctamente, de entender correctamente y de redactar correctamente o, más aún, de crear ${ }^{40}$.

\footnotetext{
${ }^{39}$ Véase la edición de la lectura en el refectorio de C. Borchling, Litterarisches und geistiges Leben, pp. 361-407, y aquí p. 395: "Ergo oportet nos laborare pro bono fundamento et totis viribus insistere docmati, ne pereat aureum clenodium doctrine, licet exigue in hoc venerando loco per nostram neglienciam et desidiam; set toto conamine elaboremus, ut de die in diem aucmentur".

${ }^{40}$ Ibidem: "Ergo in florida etate ne torpeamus per vicium accidie, set totis viribus insistamus studiis gramaticalibus, donec perveniamus ad scienciam recte legendi, recte intelligendi et recte dictandi vel componendi".
} 
¡De modo que el programa escolar también abarcaba la redacción autónoma de textos en latín y las monjas de Ebstorf no fueron formadas solo como receptoras! La expresión ne torpeamus per vicium acidie ("no vamos a estancarnos a causa del vicio de la pereza") no fue elegida aleatoriamente. La acedia, la pereza o displicencia, era uno de los siete vicios capitales, y. De entre los cuales, el de la apatía interior se contaba como uno de los defectos mayores y la Reforma exigía su superación. La enseñanza adecuada podía, por lo tanto, fomentar la actividad espiritual y la capacidad de las monjas de entender y reproducir ideas complejas. El considerable aumento de la cultura escrita que se dio dentro de los conventos a partir de la Reforma puede atribuirse al nuevo método de enseñanza, cuyo objetivo era alcanzar de forma autónoma las tareas litúrgicas y que las monjas se expresasen por escrito y redactasen sus propios textos.

\section{EXPERIENCIA: LOS CONOCIMIENTOS DE LAS MONJAS A CARGO DE UN OFICIO}

Sobre todo los antiguos conventos de mujeres poseían numerosos bienes raíces, abundantes propiedades feudales y alodiales y disponían de los derechos feudales y señoriales derivados de estos ${ }^{41}$. También los monasterios urbanos de las órdenes mendicantes contaban generalmente en los siglos XIV y XV con bienes raíces y con rentas fijas en las ciudades. No resultaba fácil administrar acertadamente grandes comunidades de mujeres que vivían en clausura, sin olvidar que estas comunidades comportaban cierta importancia política. Normalmente, las mujeres en los conventos recibían información sobre cuestiones políticas de forma indirecta, y a esto se sumaba que no tenían posibilidad de defender sus intereses por vía oral. Por estos motivos, era especialmente importante para ellas conocer con exactitud el marco legal que las atañía. Con la reimplantación de la clausura rigurosa durante la reforma monástica del siglo XV se desarrollaron formas de administración por escrito que permitían defender mejor los derechos documentados y los bienes raíces ${ }^{42}$. En los archivos de los monasterios se han conservado numerosos manuscritos en los que las mujeres recopilaron y documentaron por escrito, para la propia comunidad monástica, los conocimientos que iban adquiriendo a través de la experiencia. Esta cultura escrita que se daba en el interior de los conventos muestra al mismo tiempo una segunda cara de la vida espiritual femenina

${ }^{41}$ G. Thoma, Ökonomie und Verwaltung, pp. 297-313.

42 Ibidem.

ANuARIo de Estudios Medievales, 44/1, enero-junio 2014, pp. 309-348 ISSN 0066-5061, doi:10.3989/aem.2014.44.1.10 
durante la Baja Edad Media: el campo de acción y las competencias propias especialmente de las monjas que ostentaban cargos u oficios. Estas estaban, junto con el prior, a cargo de las tareas centrales de la administración de los bienes raíces, del abastecimiento material de las monjas de coro y de las legas. Y también era de su competencia la defensa de los derechos de la comunidad dentro de la rivalidad de poderes existentes en la región. Únicamente una base económica adecuada podía asegurar la manutención de todas las monjas que vivían en clausura durante el transcurso del año. De esta forma, las monjas desarrollaron un eficaz sistema interno de organización administrativa que se basaba en un tipo especial de anotaciones entre las que se recogen facturas, apuntes cronológicos e información interna sobre el convento y, dado su carácter polifacético, han pasado a conocerse posteriormente con el vago nombre de "crónicas" o los así llamados Hausbüicher. Gracias a estas anotaciones, las mujeres del convento se aseguraban de que su nivel de vida era el adecuado, controlaban el estado de las cuentas del convento, asentaban las bases de sus conocimientos jurídicos y seguían el desarrollo de las finanzas. Los Hausbücher solían ir acompañados de un libro de cuentas ${ }^{43}$. El hecho de documentar los conocimientos que se iban adquiriendo en el día a día era una tendencia de la época que también se practicaba en los círculos laicos. Especialmente en los círculos patricios de Núremberg se había establecido una tradición propia sobre la fijación por escrito de este tipo de conocimientos, como demuestran los Hausbücher de Ulman Stromer (1329-1407) y Nikolas Muffel (1410-1469) o los libros de familia de Anton II Tucher (1458-1524) y Lukas Rem (1481-1541) ${ }^{44}$.

Para ilustrar las características y la diversidad de esta cultura escrita que se daba en los conventos deberían bastar aquí unos pocos ejemplos. La base legal de una comunidad estaba definida por las fundaciones y los privilegios adquiridos a lo largo de la historia del monasterio, y por ello era esencial para las mujeres conocer el contenido de sus documentos y certificados con exactitud. El caso de las Clarisas de Núremberg deja apreciar especialmente el éxito que podía llegar a tener el acceso a la propia historia como base para futuras gestiones. Tras la implantación de la Reforma en el año 1452, las Clarisas de Núremberg reorganizaron el archivo de su convento en colaboración con el franciscano de Núremberg Nikolaus Glassberger y tradujeron los privilegios

43 Véase también E. Schlotheuber, Klostereintritt, pp. 321-326, 329-332. Sobre los libros de cuentas de la Baja Edad Media en general, véase la página Computatio de la Universidad de Marburgo sobre las cuentas en la Baja Edad Media y la Edad Moderna (http://online-media. uni-marburg.de/ma_geschichte/computatio) [consulta: 04/11/2013].

44 Véase B. Schmid, Schreiben, pp. 59-114. Véase también K. Arnold, S. Schmolinsky, U.-M. Zahnd (eds.), Das dargestellte Ich. 
más importantes recopilándolos en una especie de crónica ${ }^{45}$. Con su trabajo lograron crear un compendio extraordinario y profesional que proporciona rápido acceso a su propia historia: los documentos y las cartas están ordenados cronológicamente y se han convertido en la fuente de información a partir de la cual es posible conocer la historia del convento. Cada documento contiene un comentario histórico, en el cual se explica el origen de dicho documento. En un breve regesto que encabeza cada página, se resume el contenido jurídico del documento, mientras que en el cuerpo del texto se ofrece el texto completo traducido. En algunos casos el documento contiene una observación final en la que se describe el desenlace de litigios previos con el Concejo de Núremberg, los hermanos franciscanos o el obispo de Bamberg. Como podemos observar, la "crónica conventual" brindaba a las Clarisas de Núremberg ejemplos sobre el desarrollo de algunos conflictos, así como estrategias para llegar a una solución. Esta forma de autocercionamiento tuvo un éxito absoluto. Durante la visita del cardenal y humanista Johannes Bessarion el 29 de febrero de 1460, las mujeres de Santa Clara presentaron hábilmente los privilegios que les correspondían y, de este modo, hicieron frente a la exigencia de tributos del obispo de Bamberg y se protegieron contra posibles reivindicaciones futuras ${ }^{46}$. En el prólogo a la segunda parte de su "crónica", que comienza con la Reforma del convento, queda plasmada la intención que sus esfuerzos albergaban:

En la segunda parte deben describirse los hechos acontecidos desde la sagrada observancia y, sobre todas las cosas, aquellas que son indispensables para nosotras. Por ello las hermanas deben recordar siempre los hechos pasados, para que puedan gobernarse por sí mismas, también en relación a aquella cosas aún por suceder ${ }^{47}$.

Así pues, las Clarisas de Núremberg solo se veían capaces de gobernarse por sí mismas si conocían su propia historia, que, a su vez, definía el

\footnotetext{
45 Véase L. Vosding (ed.), Schreib die Reformation von Munchen gancz daher; E. Schlotheuber, Humanistisches Wissen, pp. 89-118.

46 Ibidem, pp. 95-97.

47 Múnich, BNM 1191, f. 42r: "Aber nun wern für das ander theil gesetzt die geschicht, die sich in der heiligen observantz verloffen hab. Und allem die ding, die allermaist not sind, das dasselb hab die andacht der schwester zu gedechtnus der vergangen ding, auff das sie sich mugen regirn, auch in den dingen, die kunftiglich noch zu thun wern". Los siguientes comentarios se basan en los resultados del proyecto de la DFG (Deutsche Forschungsgemeinschaft) "La alfabetización en los conventos del sur de Alemania" que ponen en relación la rica cultura escrita administrativa, que revela el profundo conocimiento de las monjas en la materia, con las colecciones de libros de sus bibliotecas y los libros para uso privado. Sólo de esta manera se pueden reconocer las diversas interdependencias entre lo teológico, lo literario y lo "administrativo"; veáse también: http://www.phil-fak.uni-duesseldorf.de/geschichte/lehrstuehle/mittelalterliche-geschichte/forschung/dfg-projekt-schriftlichkeit-in-sueddeutschen-frauenkloestern/ dominikanerinnenkloster-altenhohenau/\#c47486.
} 
margen de acción de las mujeres religiosas en el sistema político de Nürnberg. Desde la Reforma y el restablecimiento de la clausura, las exigencias a las mujeres habían aumentado sensiblemente. A causa de las malas experiencias vividas con los priores y procuradores, los conventos femeninos empezaron a hacerse cargo de la administración de sus bienes de forma cada vez más autónoma. Había que organizarse y hacer frente a la manutención diaria de la comunidad monástica, que comprendía entre ochenta y cien mujeres (incluidas las legas), de la administración de los altares y de las obligaciones para las misas de ánimas. Por esto era importante que todos estos conocimientos se transmitieran dentro de la comunidad.

También se han conservado ejemplos que documentan la rutina diaria de los conventos de monjas dominicas. En Altenhohenau las hermanas recopilaban información interna del convento en sus Hausbücher o libros de cuentas $^{48}$. Entre los gastos e ingresos anotados en estos libros también encontramos un breve informe sobre la implantación de la Reforma en el año 1465. De hecho, existe un libro en el que las religiosas de Altenhohenau registraron cuidadosamente sus ingresos durante más de veintiséis años (1494-1520) que es apenas conocido y que se encuentra actualmente en la Biblioteca Estatal de Baviera ${ }^{49}$. Este libro reproduce el cuidado con el que las mujeres llevaban la valiosa economía conventual. Entre otras cosas, la arquera (durante muchos años Anna Hirschauer) registraba bajo diferentes categorías y con la máxima precisión los ingresos territoriales, los procedentes del vino y el aceite, del ganado, del arrendamiento de tierras, de las tasas por matrimonio y las multas a los siervos y los ingresos de las arcas de la iglesia monástica. El día de San Miguel hacía la liquidación de las cuentas con la priora y esta, a su vez, le asignaba a la procuradora el dinero necesario para las compras y los gastos ${ }^{50}$. Este riguroso balance anual del dinero les permitía a las mujeres que estaban al frente de estos tres oficios calcular en cualquier momento las posibilidades económicas de la comunidad.

\footnotetext{
48 Múnich, BHSA, Altenhohenau KL 12 f. 497r. Véase también M.-L. Ehrenschwendtner, Die Bildung, pp. 311-316.

49 Múnich, BSBM, Clm 697. Véase también Digitalisat: Despripción de manuscritos y clasificación histórica http://www.phil-fak.uni-duesseldorf.de/geschichte/lehrstuehle/mittelalterliche-geschichte/forschung/dfg-projekt-schriftlichkeit-in-sueddeutschen-frauenkloestern/ dominikanerinnenkloster-altenhohenau/\#c47486 [consulta: 04/11/2013].

50 "Abgerait mit der zinsmaisterin, swester Anna Hischawerin, an sant Ruprechts abent vor sant Michaelstag von allen einnemen des LXXXXIIII jar [1494] von sant Mauricius tag pis an den obgeschriben tag" (BSBM, Clm 697, f. 7r). Del los 730 marcos, 3 chelines y 3 denarios la provisora recibió un total de 709 marcos, 3 chelines y 3 denarios; 21 marcos se podían depositar en el depositum. Cuando en el año 1502 se ajustaron las cuentas, estas salieron exactas: "Item abgezogen alles ausgebens der schaffnerin und einnemens der zinsmaisterin. Die zwu hauptsumen gegenainander, so get es geleich aus und ist nichts übrig. Deo gracias" (ibidem, f. 69r).
} 
También las Dominicas de St. Gallen asentaron tras la Reforma nuevas bases con las que se definía el nuevo campo de acción de su comuni$\mathrm{dad}^{51}$. En un manuscrito conocido como Schwesternbuch o "Libro de monjas", Elisabeth Muntprat registró desde 1483 hasta 1486 toda la correspondencia entre la priora Kunigunde Haller de Núremberg y la dirección de su propia orden. Para organizar la vida del propio monasterio acorde a la Reforma, las hermanas se regían por las instrucciones que les llegaban por escrito desde Núremberg y que tenían carácter normativo. Al igual que en el convento de las Clarisas de Núremberg, este nuevo comienzo viene marcado en gran medida por la preservación de la propia historia conventual: en el "Libro de monjas" reconstruyeron la historia del convento mediante los documentos en forma de regestos (1228-1488) y añadieron informes sobre los capítulos provinciales para mantenerse al día sobre las resoluciones más importantes de la orden. Además, agregaron resoluciones de la propia congregación y una lista de las superioras del convento con indicaciones sobre el tiempo que desempeñaron este cargo. Contaban además con un libro becerro, gracias al cual era posible conocer a fondo la base económica del convento, y las notas necrológicas fueron reorganizadas para sistematizar las obligaciones acumuladas a lo largo del tiempo para con los difuntos. Andreas Rüther opina acertadamente que estos "Libros de monjas" reúnen noticias valoradas como dignas de recuerdo altamente subjetivas ${ }^{52}$. Y sin embargo, no se trata únicamente de una recopilación arbitraria de información, sino de una selección llevada a cabo de forma cuidadosa y estructurada con propiedad. Como consecuencia del restablecimiento de la clausura rigurosa en la mayoría de los conventos femeninos durante la Reforma del siglo XV del Imperio Romano Germánico, las mujeres examinaron de nuevo y a fondo las bases teológicas, religiosas y económicas de su propia forma de vida. Y además, buscaron nuevas formas para hacerse respetar en un mundo basado cada vez más en la cultura escrita y en la imposición de poder y conflictos por vía judicial.

\section{COLECCIONES BIBLIOGRÁFICAS Y BIBLIOTECAS MONÁSTICAS}

Los estudios sobre la cultura escrita de los conventos femeninos de la Baja Edad Media siguen siendo uno de los grandes objetivos de la investigación ${ }^{53}$. Esto no concierne solamente a las bibliotecas de los conventos, pues

${ }^{51}$ A. Rüther, Schreibbetrieb, pp. 653-677.

52 Ibidem, p. 657.

${ }^{53}$ Véanse los dos proyectos que se han dedicado a algunas de las bibliotecas de los conventos de mujeres del norte y del sur de Alemania respectivamente: http://www.hab.de/de/home/ue- 
los libros se encontraban esparcidos en diversos lugares tanto en los monasterios de hombres como de mujeres. Los libros litúrgicos se guardaban en el coro y en la sacristía; en la sala capitular debía conservarse al menos una copia de las reglas de la orden, un obituario o también los llamados libros capitulares. En los conventos de monjas cistercienses se hallaba en el claustro, entre el ala este y norte, un armario para libros (armarium) con, sobre todo, literatura contemplativa y devocional. En el refectorio se guardaba una colección bibliográfica especial que estaba pensada para la lectura durante las comidas y en la enfermería se podía encontrar, sobre todo para los enfermos, literatura devocional y de consolación, aunque es probable que la enfermería también albergase libros de medicina y herbarios. Tanto las monjas como los monjes guardaban en las celdas libros que habían recibido como regalo, herencia o que habían copiado ellos mismos, además de libros prestados de la biblioteca ${ }^{54}$. Los abades y las abadesas solían contar con una biblioteca de consulta ajustada a sus tareas. Finalmente, el archivo monástico también contenía, además de documentos, cartularios y libros de contabilidad, libros becerros y libros feudales, así como las ya mencionadas crónicas o los Hausbücher. Los conocimientos sobre la extensión, el tipo de contenidos y la organización interna de estas grandes y pequeñas colecciones bibliográficas son bastante rudimentarios. Los intentos por reconstruir alguna de estas bibliotecas de los monasterios femeninos siguiendo las indicaciones de los manuscritos e incunables que nos han llegado hasta hoy tropiezan rápidamente con la dificultad de que apenas existen parámetros de comparación ${ }^{55}$. El hecho de que en los monasterios de mujeres a menudo se hayan conservado mayormente manuscritos de sermones y textos contemplativos no significa que las bibliotecas monásticas de las congregaciones solo, o en su mayoría, abarcaran libros de este género o similares. Los escritos patrísticos, así como los libros de sentencias o la literatura canónica eran muy codiciados y solían ser donados antes o durante la disolución de los conventos. Otros factores que aumentan la incertidumbre sobre el destino de los ejemplares de las bibliotecas son la pérdida y venta de libros así como los incendios en los conventos. A menudo, tras la disolución de los conventos de mujeres y la incorporación de los manuscritos a las colecciones especiales de las bibliotecas modernas, se han perdido los vínculos con su origen, por lo que resulta extremadamente difícil reconstruir las primitivas

ber-uns/kontakte-und-organisation/pd-dr-britta-juliane-kruse.htm) y http://www.phil-fak.uniduesseldorf.de/geschichte/lehrstuehle/mittelalterliche-geschichte/forschung/) [consulta: 04/11/ 2013]. Véanse también los catálogos: B. Kruse, Rosenkränze, así como D. Bell, What Nuns Read.

${ }^{54}$ Véase Mittelalterliche Bibliothekskataloge para encontrar información sobre el orden de los libros y el tipo de contenidos; véase también E. Schlotheuber, Die Franziskaner, pp. 76-80.

55 Véase A. Schromm, Die Bibliothek y también F. Eisermann, Reseña, pp. 475-478. 
colecciones. Además, apenas existen catálogos de bibliotecas medievales que ofrezcan información sobre la extensión y el sistema de las bibliotecas monásticas $^{56}$. Un inventario bibliotecario y apenas conocido del año 1386 de las Dominicas del monasterio de St. Marien en Lemgo (Westfalia) registra sesenta y cinco títulos en setenta y cinco tomos que estaban clasificados según tamaño y encuadernación (sencilla y con cubierta) ${ }^{57}$. Es evidente que este inventario de libros fue realizado por la bibliotecaria que, además, tenía a su disposición un pequeño taller de encuadernación (He sunt pertinentia ad officium librarie) ${ }^{58}$. La mayor parte de los libros estaban escritos en latín y unos pocos, colocados en el estante más alejado, estaban escritos en lengua vernácula. El contenido de esta biblioteca monástica, de índole científico-natural, se diferencia mucho de los fondos de los monasterios femeninos del siglo XV que conocemos ${ }^{59}$; especialmente impresionante es su refinada colección de literatura escolar latina ${ }^{60}$. Queda claro además que las Dominicas de Lemgo poseían pequeñas colecciones de libros de su propiedad de las que a su muerte regalaban algunos de sus manuscritos a la biblioteca monástica.

Si partimos de los manuscritos e incunables conservados, es inevitable que surja la pregunta metodológica sobre cómo hacer para poder comparar fondos de manuscritos e incunables que muchas veces nos han llegado por caminos diferentes o de pura casualidad. Una posibilidad sería dilucidar el primitivo contexto funcional de estos libros que han llegado hasta nosotros y clasificarlos conforme a los géneros literarios que, según se ha demostrado, existían en los monasterios de mujeres ${ }^{61}$. Estos fondos bibliográficos pueden clasificarse en dos grandes áreas funcionales: la primera de ellas comprende los libros litúrgicos que, generalmente, se guardaban en la sacristía o en el coro de las monjas; en la segunda categoría se encuentran los libros para la lectura conjunta o privada. Esta última categoría se puede subdividir en bíblica, glosas y comentarios de la Biblia, escritos patrísticos, sumas y sentencias, libros de catequesis, literatura confesional, relatos y biografías de santos, traduccio-

56 A. Willing, Die Bibliothek; Mittelalterliche Bibliothekskataloge, vol. III-3 (Bistum Bamberg, catálogo de la biblioteca del monasterio Katharinenkloster de Núremberg, pp. 579-637).

$57 \mathrm{SAD}, \mathrm{L} 110 \mathrm{~B} \mathrm{n}{ }^{\circ} 18$. "Liberaria sororum in Lemego libros continet hic conscriptos hiis exceptis quos chorus habet necessarios pro divino officio peragendo". Véase J.F. Hamburger, E. Schlotheuber, Books in Women's Hands. Hay una edición del catálogo de la biblioteca en preparación.

${ }^{58} \mathrm{SAD}, \mathrm{L} 110 \mathrm{~B} \mathrm{n}^{\circ} 18$, f. 10r.

${ }^{59}$ Véase W. Williams-Krapp, Die Bedeutung, pp. 189-205.

${ }^{60}$ Véase para ello J.F. Hamburger, E. Schlotheuber, Books in Women's hands.

${ }^{61}$ Este planteamiento fue propuesto por la DFG en el proyecto Schriftlichkeit in süddeutschen Frauenklöstern, véase: http://www.phil-fak.uni-duesseldorf.de/geschichte/lehrstuehle/mittelalterliche-geschichte/forschung/dfg-projekt-schriftlichkeit-in-sueddeutschen-frauenkloestern/ [consulta: 04/11/2013]. 
nes litúrgicas, comentarios y meditaciones litúrgicas, literatura de sermones, ejercicios espirituales, libros de oraciones y devocionarios, ordenaciones y comentarios a la regla, derecho canónico, medicina, filosofía, enciclopedias y ciencias naturales, así como gramáticas. Sin duda, para conocer íntegramente el horizonte intelectual de las religiosas en la Baja Edad Media, no sería adecuado limitar, como se ha hecho, sus conocimientos a los campos clásicos de la literatura, la teología y la filosofía, pues no se estaría haciendo justicia al particular mundo conventual femenino y todo lo que este implica. Las facultades y el potencial de innovación que las monjas desarrollaron para dejar constancia escrita de las tareas organizativas y económicas y para conservar la memoria cultural de la comunidad, representan un campo de conocimiento amplio y muy importante. Estas competencias de las mujeres apenas han sido objeto de estudio porque no han sido puestas en relación con la historia de los conventos, sus bibliotecas y los manuscritos e incunables. Únicamente cuando se tienen en cuenta los Hausbücher y la documentación administrativa, salta a la vista el desarrollo religioso, económico y social de las comunidades femeninas en todas sus polifacéticas interdependencias y puede reconocerse el papel central jugado por la cultura escrita a nivel cognitivo, organizativo y de reflexión en todas sus dimensiones.

Hoy en día sabemos que las comunidades femeninas poseían bastante más literatura especializada en latín de lo que la investigación ha supuesto durante mucho tiempo. Las Clarisas de Brixen, por ejemplo, contaban en el siglo XV con una amplia sección de derecho canónico y de rigurosa literatura patrística en latín ${ }^{62}$. Gran parte de la literatura que las dominicas del sur de Alemania y las clarisas consultaban para cuestiones religiosas, estaba probablemente escrita en lengua vernácula. Pero aun así, sus bibliotecas contenían a menudo amplias secciones de escritos en latín. Por las compras de libros de las Dominicas de Altenhohenau (cerca de Múnich) de 1482 a 1513 podemos deducir que adquirieron y utilizaron los escritos en lengua latina con un objetivo determinado. Los títulos de los libros están recopilados en el libro de cuentas del convento, en el que los libros en latín están registrados separados de los libros en alemán ${ }^{63}$. Esto se correspondería con su disposición en la biblioteca, donde, tal y como preveía Johanes Meyer en el libro de las profesiones, también se encontraban separados: En el caso de hallarse libros en latín en un

62 D. Mauss, Benedictus Füger, pp. 292-301; D. Mauss, Benedictus Füger (continuación), pp. 245-253, pp. 292-301. En lo que respecta a la reconstrucción de la biblioteca, este autor diferencia entre los fondos de las clarisas y los de sus pastores, los franciscanos.

63 Múnich, BHSA, Altenhohenau KL 12, Hausbuch f. 505r-506r. Véase Digitalisat y la descripción en http://www.phil-fak.uni-duesseldorf.de/geschichte/lehrstuehle/mittelalterlichegeschichte/forschung/dfg-projekt-schriftlichkeit-in-sueddeutschen-frauenkloestern/dominikanerinnenkloster-altenhohenau/\#c47482 [consulta: 04/11/2013]. 
convento, estos deben conservarse y ordenarse aparte, al igual que los libros alemanes tienen su orden $^{64}$. Es interesante que los libros en latín estuviesen organizados de forma diferente a los libros en lengua vernácula. En general, la biblioteca de Altenhohenau tuvo que ser impresionante. Ya a finales del siglo XIII y principios del siglo XIV el convento recibió una donación de una colección de libros en latín ${ }^{65}$. En el año 1496 se adquirió un volumen con la intención de ser usado como catálogo de la biblioteca ${ }^{66}$. Las compras de pergamino (363 pieles entre 1492 y 1499) indican la existencia de un scriptorium y de una vivaz actividad copista en el convento ${ }^{67}$. A finales del siglo XV las dominicas adquirieron muchos más libros en latín que en alemán. En algunos casos se añadió el año de la compra, de lo que se deduce que la lista se llevaba esencialmente de forma cronológica. De las obras latinas se adquirieron primero la Pantheologia, una suma teológica del dominico Rainerius Jordanis de Pisis $(† 1348)^{68}$, un predig puch de Johannes Nider -quizá el conjunto de sermones para todo el año (Sermones totius et de sanctis cum quadragesimali) ${ }^{69}$ y la Biblia con la Glossa ordinaria ${ }^{70}$. En el año 1484 las hermanas compraron los sermones latinos del dominico Antonio de Florencia (1389-1459) por ocho florines renanos. Seis años más tarde se le pagarían doce florines renanos a la hermana Katharina Frauenhofer por un Libro de Horas, un manuscrito procesional y un tomo con el Réquiem. Por lo visto, en este caso se remuneraba a las propias hermanas por los gastos y por sus esfuerzos, mientras que en 1491 se le pagó a la hermana de Núremberg, Appolonia Imhof, que antaño había dirigido la reforma en Altenhohenau, un total de seis florines renanos por otros manuales litúrgicos ${ }^{71}$. El título Gorro über die bibel des alten und newen testamentz probablemente se refiera a la obra Postillae in vetus et novum tes-

64 J. König, Die Chronik, y en esta obra, véase: Ämterbuch des Johannes Meyer, p. 202: "Doch wo man hatt von innen in dem closter die latinschen bücher, di mag man nach ordnung bysunder legen, und die tützschen bücher och nach ordnung bysunder'. Véase, en general, K. Christ, Mittelalterliche Bibliotheksordnungen, pp. 1-29.

65 Mittelalterliche Bibliothekskataloge, vol. IV-2 (obispado de Frisinga).

66 Múnich, BHSA, KL 12, Hausbuch f. 505v: "Item umb ein puch in die liberey, ist ein register der andern pucher, dedit LXIII d. im 96 jar”.

67 Ibidem, f. 506r.

68 Probablemente se trate del incunable; la Pantheologia se editó varias veces hasta 1482.

${ }_{69}$ El libro de sermones abarca series completas de sermones dominicales, sermones de santos y sermones del ayuno.

70 Múnich, BHSA, Altenhohenau KL 12, Hausbuch f. 505r: "Item umb das puch glosam ordinariam uber die ganczen bibeln mit dem text XIIII lb anno domini $\mathrm{M}^{\circ} \mathrm{IIII}^{\mathrm{c}}$ und im LXXXII jar in der vasten [1482]"'. Probablemente se trate de la Biblia cum glossa ordinaria, impresa antes de 1480 y publicada por el editor de Núremberg, Anton Koberger junto con el impresor Johann Amerbach de Basilea; Gesamtkatalog der Wiegendrucke, 4282. Véase este catálogo en la red: http://www.gesamtkatalogderwiegendrucke.de/ [consulta: 04/11/2013].

71 Múnich, BHSA, Altenhohenau KL 12, Hausbuch f. 505r. 
tamtentum del dominico Nicolas de Gorran ( $†$ 1295). Además se adquirieron otros salterios, un obituario y varios procesionales. También se escogió para Altenhohenau la obra Catholicon que contenía diversos tratados sobre temas básicos de gramática y lexicografía que recopiló el dominico Juan de Génova (Johannes Balbus) en $1286^{72}$. Las siguientes adquisiciones complementaban la sección de derecho canónico: las dominicas compraron las Decretales de Gregorio IX (1230-1234), la Clementinae (la Decretal de Clemente V, 13051314), el Liber sextus (la Decretal de Bonifacio VIII, 1294-1303) y el Decretum Gratiani $^{73}$. En 1497 se compró una recopilación con los privilegios de la orden. El libro llamado Bartholomeus probablemente haga referencia a la obra Casus decretorum revisada por Bartholomäus von Brixen $(† 1258)$ o a la conocida enciclopedia De proprietatibus rerum del franciscano Bartolomé Ánglico (aprox. 1240).

La lista de los libros alemanes es bastante más escueta. Bajo el título umb teutzsche pucher se recoge dentro del año 1494 un gasto total de seis florines para un libro llamado Speculum ${ }^{74}$. Le sigue un pequeño volumen que contenía la interpretación de los Diez Mandamientos ${ }^{75}$ y en 1504 compraron las dominicas por cuatro chelines sermones del dominico Juan Taulero $(\dagger 1361)^{76}$. Del predicador estrasburgués Juan Geiler de Kaisersberg (14451510) compraron en 1509 Das irrig Schaf, y la entrada que aparece a continuacón, Item umb II teucsche aufgetruckte pucher genant kayser perg VIII s., probablemente se refiera a la compra en 1508 de los sermones impresos en alemán de Geiler y/o a su ciclo de sermones der Bilger, que se imprimió en 1494. Es probable que el libro der granat appfel aluda a la obra correspondiente de Geiler von Kaiserberg o, quizá a la obra Malogranatum (Das buch granatapfel) de Gallus von Königssaal († alrededor de 1370). A parte de esto solo se compró una Biblia en dos tomos en 1510. De la pluma del predicador de Estrasburgo procede el teucsch puch genant cristenlich bilgerschaft

\footnotetext{
${ }^{72}$ Probablemente se trate de un incunable; el Catholicon, por ejemplo, del cual se editaron numerosos ejemplares en 1460 (300 ejemplares) en Maguncia (impresor desconocido), y tuvo cuatro ediciones antes de 1482 (Gesamtkatalog der Wiegendrucke, 3182-3185).

73 "Item umb ein puch genant decretum III $1 / 2$ r. gülden VIII $1 / 2 \mathrm{~d}$., hat uns vater Wolfgang kauft zu Auspurg im 97 jar”. Véase E. Friedberg (ed.), Corpus iuris canonici, vol. I.

74 "Item umb ein teucsch puch genant speculum VI s. im anno 1491"; Múnich, BHSA, Altenhohenau KL 12, Hausbuch, f. 507r. El título no se puede identificar de forma más detallada.

75 "Item umb ein teucsch puch genant artickel des gelaubens LXX d." (Múnich, BHSA, Altenhohenau KL 12, Hausbuch, fol. 507r). Quizás se trate del incunable Erklärung der zwölf Artikel des christlichen Glaubens, Ulm: Konrad Dinckmut, 21 Agosto 1485 (Gesamtkatalog der Wiegendrucke, 9379).

${ }^{76}$ Es posible que también aquí se trate de un incunable. Los sermones de Tauler fueron impresos en Leipzig en 1498 por Konrad Kachelofen (Sermon des großgelarten doctoris Johannis Tauleri). Véase al respecto H. Otto, Vor- und frühreformatorische Tauler-Rezeption.
} 
zum ewigen vaterlant, manuscrito que las dominicas adquirieron en 1513. Ese mismo año se hicieron también con el libro especializado del médico de Estrasburgo Hyeronimus Brunswig (1450-1512/13 aprox.), el Liber de arte distillandi, también llamado Micarium, que contenía, sobre todo, indicaciones sobre cómo extraer medicinas a partir de plantas ${ }^{77}$.

En Altenhohenau también había una bibliotecaria encargada de la biblioteca y de las nuevas adquisiciones. Sobre la biblioteca y el cargo de la bibliotecaria escribe Johannes Meyer en su libro de las profesiones: para desempeñar el cargo de bibliotecaria es necesario sentir un gran amor y afecto por los libros. La bibliotecaria debe encargarse de que los libros se depositen en un lugar adecuado y seguro, resguardados de los temporales y la lluvia. La biblioteca debe estar bien aireada, la estancia debe tener forma similar a una celda y ser tan grande o tan pequeña como lo requiera la colección bibliográfica. Pero se debe tener en cuenta que, si aumenta la cantidad de libros, también la biblioteca puede crecer. Los armarios para los libros (armaria) o los atriles en los que se colocarán los libros deben ser de madera. Pero la biblioteca en sí debe estar construida en piedra para prevenir mejor la humedad, el moho u otros daños. Los libros tienen que estar colocados en los atriles o en los armarios según la materia tratada ${ }^{78}$. La bibliotecaria era la encargada de clasificar los géneros literarios por materias y de dotar los libros de signaturas topográficas. Para ello, en el libro de las profesiones figuraba una explicación sobre este orden propio de las bibliotecas medievales: los textos bíblicos se colocaban en el atril A, las glosas en el B, los escritos patrísticos en el atril C, en el D las Collationes patrum, etc. Entre las tareas de la bibliotecaria se contaban también el registro de los volúmenes en el catálogo de la biblioteca y la revisión periódica de los libros de consulta. Según las indicaciones de Johannes Meyer, se da por hecho que los conventos de mujeres contaban con bibliotecas bien surtidas, con secciones dedicadas a escritos latinos y alemanes y que, básicamente, estas bibliotecas estaban organizadas como las colecciones bibliográficas de los conventos de hombres. Podemos suponer que la biblioteca de Altenhohenau, que durante los años finales del siglo XV fue continuamente ampliada y actualizada mediante la adquisición de nuevos ejemplares, estaba organizada de forma similar.

En el norte de Alemania la biblioteca más conocida es la del monasterio benedictino femenino de Ebstorf, donde se han conservado un total de

77 Múnich, BHSA, Clm 697 f. 30r.

78 J. König, Die Chronik, y en esta obra, véase: Ämterbuch des Johannes Meyer, p. 202. Véase, en general, E. Lehmann, Die Bibliotheksräume.

ANUARIO DE ESTUdios MedieVAles, 44/1, enero-junio 2014, pp. 309-348 ISSN 0066-5061, doi:10.3989/aem.2014.44.1.10 
cincuenta y un códices ${ }^{79}$. Casi todos estos manuscritos que nos han llegado hasta hoy fueron confeccionados en el siglo XV, durante o después de la Reforma. Por lo visto, una parte de los manuscritos tuvo que ser sacrificada en pro de los códices litúrgicos, necesarios para la reforma litúrgica. Como se puede leer en la obra Lectura en el refectorio de la monja anónima de Ebstorf:

Muchos esfuerzos hicieron nuestras madres, pues, a menudo, aquello que debían cantar al día siguiente, lo debían copiar la noche anterior. Primero se eligieron doce hermanas para la nueva celebración de la misa; seis en un coro y seis en otro. El resto de hermanas quedaban dispensadas hasta que viesen y aprendiesen la nueva forma de cantar. Todos los libros litúrgicos (leccionarios, graduales y antifonarios) debían retirarse, pues estaban tan ajados y dañados que debían reescribirse de principio a fin $^{80}$.

A través de los cuatro breviarios que se han conservado, se percibe la influencia de la Reforma de Bursfeld. Dado que el convento sufrió una notable falta de libros tras la implantación de la Reforma, se hizo lo que se pudo para remediarlo:

En los comienzos de la Reforma había una gran deficiencia de libros. A menudo las hermanas tenían que escribir sobre un papel aquello que se debía leer o cantar al día siguiente ${ }^{81}$.

En la etapa siguiente se construyó prácticamente una nueva biblioteca monástica. Esta debía poner a disposición del convento los escritos necesarios para la implantación espiritual de la Reforma, para la comprensión de la catequesis y las obras moralizadoras, de las oraciones y del oficio divino. Se han conservado tres extensos manuscritos de sermones en bajo alemán con traducciones de sermones de los dos dominicos Jacobo de la Vorágine $(†$ 1298) y Johannes Herolt $(\dagger 1468)$, del cisterciense Bernardo de Claraval $(\uparrow 1153)$ y del ermitaño de San Agustín Heinrich von Friemar el Viejo $(†$ 1340). También se encontraba aquí el Libro de la sabiduría eterna del do-

79 E. Schlotheuber, Ebstorf und seine Schülerinnen, pp. 169-221; R. Giermann, H. Härtel (eds.), Handschriften.

${ }^{80}$ C. Borchling, Litterarisches und geistiges Leben, p. 389: "Magnum enim laborem tunc habuerunt matres nostre, quia sepe ea que cantanda erant per noctem die precedenti scribebant. Duodecim sorores in primo erant constitute, sex in uno choro et sex in alio, que divinum officium persolvebant. Alie omnes erant suspense, donec viderent et docerent modum. Omnes libri cantuales quam lectionales, gradalia et antiphonarii oportebant deponi, que incidebantur ac delebantur et ex novo omnia scribebantur".

${ }^{81}$ Ibidem, p. 391: "In prima inchoatione sancte reformacionis nostre matres habebant magnam carenciam librorum; sepius sorores in sedulis et cartis scribebant que per diem cantare aut legere tenebantur". 
minico Heinrich Seuse $(† 1366)$, que pertenecía a los libros de devoción muy difundidos en los siglos XIV y XV. La existencia de los escritos de Seuse demuestra que sus obras eran apreciadas en Ebstorf. Servían además como lectura para las monjas, pues Seuse se había dedicado intensamente a la cura animarum en los conventos de mujeres. La biblioteca monástica ofrecía asimismo el Horologium sapientiae, un texto revisado y ampliado del Libro de la sabiduría eterna en lengua latina, con reflexiones adicionales sobre asuntos monásticos y de estudio. El Horologium sapientiae formaba parte de un códice de la biblioteca del convento redactado en parte en latín y en parte en alemán (Ms. IV 12) en el que se encontraban recopilados una serie de escritos de los autores místicos más importantes: el maestro de Seuse en el Studium generale dominico de Colonia, Meister Eckhart (†1328), estaba representado con Rede der unterscheidunge, así como con sermones y textos compilados de sus escritos, que, por su gran numero, nos dejan constatar que también el místico Maestro Eckhart era muy estimado en Ebstorf. Junto con estos textos se encuentran también los sermones del dominico Johannes von Sterngassen (director del Studium Generale de Colonia alrededor de 1320) y un fragmento de De spiritualibus ascensionibus del destacado representante de la devotio moderna Gerard Zerbolt van Zutphen (†1398), junto al Stimulus amoris del Pseudo-Buenaventura ${ }^{82}$ y otros escritos del Pseudo-Bernardo. Este códice ofrecía también lo más famoso de la literatura reformista espiritual, el manuscrito De imitatione Christi de Tomás de Kempis (†1471) y, asimismo, la muy difundida Vita Christi de Ludolfo de Sajonia $(\dagger 1378)$, quien originariamente perteneció a la Orden Dominica, pero más tarde entraría a formar parte de la Orden de los Cartujos. Si tenemos en cuenta además los fragmentos del Liber specialis gratiae de la autora mística Mechthild von Hackeborn, fallecida en 1289/1299 en el convento femenino cisterciense Helfta, se pone en evidencia una imagen impresionante de la recepción de los escritos místicos, en especial los de los teólogos dominicos, que fueron los que, sobre todo en el curso de sus actividades pastorales, más escribieron para las monjas. El manuscrito (IV 14) del siglo XIV, todo él en latín, contenía textos de los padres de la Iglesia: Augustinus, Ambrosius y Hieronymus. En otro códice (IV 29) se podían leer decisiones importantes del derecho canónico, a saber, las Decretales del Papa Gregorio IX (fallecido en 1241). Sin embargo, para poder leer las Decretales y muchos otros de los escritos, también copiados y adquiridos tras la Reforma en el siglo XV expresamente para la vida en el convento, había un requisito indispensable: además de dominar la lengua latina, se debía conocer la argumentación escolástica.

\footnotetext{
${ }^{82}$ F. Eisermann, Stimulus amoris.
} 


\section{RESUMEN}

Los monasterios femeninos medievales conformaban, ya desde el primer cristianismo, un espacio vital singular. Por un lado, la vida monástica brindó a las mujeres religiosas la oportunidad de desarrollarse considerablemente, en especial, gracias al acceso a una formación intelectual, pero por otro lado, sobre todo a causa de la clausura, se encontraron particularmente limitadas. Aun así, y pese a esta vida intramuros, las comunidades femeninas estaban estrechamente vinculadas a la sociedad medieval. Representaban centros religiosos, económicos y sociales de gran importancia y alto poder económico que, marcados por su entorno social y por el momento de su fundación, la orden, el idioma, las tradiciones religiosas y literarias así como el derecho y las costumbres, ejercían, a su vez, una gran fuerza de atracción. A través de estas relaciones de interdependencia, así como de la competencia entre ellos, contribuyeron al desarrollo manifiesto de "paisajes monásticos" particulares. Si bien un "paisaje monástico" no se da históricamente, sino que se configura según el enfoque y el modo de interpelar de la propia investigación, permite poner de relieve, a través de una aproximación metodológica, las características particulares de cada "paisaje" y, por ende, comparar la cultura literaria y material de los monasterios femeninos. Valdría la pena confirmar con ulteriores estudios comparados la idoneidad de este método de investigación.

Resulta difícil formular una teoría final sobre el mundo literario y el horizonte intelectual de las mujeres religiosas de la Baja Edad Media. Las diferencias que observamos en el nivel cultural de las monjas y en los contenidos de sus bibliotecas solo se pueden explicar mediante una imagen detallada y basada en estudios individuales. En todo caso, es obvio que la escasa información obtenida a través de la fuentes normativas (reglas monásticas, consuetudines y estatutos) acerca de la formación intelectual de las monjas, solo se puede tomar como punto de partida. Gracias a los conocimientos de latín que las religiosas necesitaban para poder llevar a cabo las tareas litúrgicas, tuvieron acceso a la tradición culta del Medievo europeo. La enseñanza en los conventos femeninos tenía un alto nivel y comprendía, en general, muchos años de clases intensivas en las escuelas monásticas. Las muchachas solían entrar en el convento a edad muy temprana, y las mismas monjas se encargaban de educarlas y formarlas, ya que en las instituciones educativas públicas, como las escuelas de latín y universidades, las mujeres no eran admitidas. Algo que en todo caso es válido para todo el Imperio como demuestran los múltiples intentos de transgredir esta norma ${ }^{83}$. No sorprende, pues, que también en este

${ }^{83}$ E. Schlotheuber, Per vim et metum, pp . 165-176. 
punto podamos reconocer un espacio erudito concreto, en el que el conocimiento teológico-religioso estaba estrechamente vinculado a la liturgia y su interpretación. Sin embargo, los diversos campos de conocimiento de los conventos femeninos no se limitaban a los conocimientos teológicos, litúrgicos y literarios, sino que abarcaban también amplios saberes de tipo administrativo y jurídico. Estos saberes (como saberes ligados a la escritura) estaban adaptados a las exigencias particulares de la administración, desde la clausura, de la familia monástica y de la economía del convento.

Estos ámbitos de conocimiento se reflejan en la estructura de las bibliotecas monásticas, pero también en la documentación administrativa de sus archivos. El ambicioso perfil literario de las bibliotecas de las Clarisas de Brixen, de las Dominicas de Altenhohenau y de St. Marien en Lemgo, o de las Benedictinas de Ebstorf, muestra que la imagen defendida hasta ahora por la investigación sobre las bibliotecas monásticas femeninas, como colecciones de literatura puramente vernácula y de devoción contemplativa, debe ser renovada. Las investigaciones futuras han de sacar a la luz nueva e inesperada información.

\section{BIBLIOGRAFÍA CITADA}

FUENTES NO IMPRESAS:

\section{Detmold, SAD}

L110 B núm. 18 Catálogo de la biblioteca del monasterio dominico de St. Marien, Lemgo

\section{Ebstorf, Archivo monástico}

Ms. IV 12

Ms. V 2

Ms. V 3

Ms. V 4

Ms. V 6a
Tomás de Kempis, Ludolfo de Sajonia, Meister Eckhard, Enrique Suso

Himnos, vocabulario, gramática, informes sobre la Reforma

Expositio hymnorum, hymnar, grammaticalia, musicalia

Ejercicios de la escuela monástica

Regulae grammaticales (siglo XV, fragmento)

\section{Lüne, Archivo monástico}

Ms. 6

Ms. 13

Ms. 14
Gramática latina (siglo XV)

Crónica (anales) del monasterio (1481-1530)

Libro de estatutos (1481-1500) 
Ms. 15

Ms. 23

Ms. 24

Ms. 30

Ms. 31

\section{Múnich, BNM}

Ms. 1191
Copiale litterarum (1483-1535)

Libro de profesiones de la sacristía (finales del siglo XV-1512/13)

Notas sobre la elección de la Priora Mechthild Wilde (1504-1535)

Copiale litterarum (siglo XVI)

Copiale litterarum (siglo XVI)

Crónica de la Clarisas de Núremberg (copia en limpio)

\section{Múnich, BHSA}

Altenhohenau KL 12

Hausbuch del monasterio dominicano de Altenhohenau

\section{Múnich, BSBM}

Clm 697

Libro de ingresos del monasterio dominicano de Altenhohenau

RECURSOS ELECTRÓNICOS:

Berlin, Staatsbibliothek:

http://www.gesamtkatalogderwiegendrucke.de/ [consulta:04/11/2013]

Düsseldorf, Heinrich Heine-Universität:

http://www.phil-fak.uni-duesseldorf.de/geschichte/lehrstuehle/ mittelalterliche-geschichte/forschung/dfg-projekt-schriftlichkeit-insueddeutschen-frauenkloestern [consulta: 04/11/2013]

Marburg, Universität:

http://online-media.uni-marburg.de/ma_geschichte/computatio [consulta: 04/11/2013]

Wolfenbüttel, Herzog-August Bibliothek:

http://www.hab.de/de/home/ueber-uns/kontakte-und-organisation/ pd-dr-britta-juliane-kruse.html [consulta: 04/11/2013] 
LITERATURA:

Angenendt, Arnold, Geschichte der Religiosität, Darmstadt, Primus, 2000. (2nd. reworked ed.).

Arnold, Klaus; Schmolinsky, Sabine; Zahnd, Urs-Martin (eds.), Das dargestellte Ich. Studien zu Selbstzeugnissen des späten Mittelalters und der Frïhen Neuzeit, Bochum, Dieter Winkler, 1999. (Selbstzeugnisse des Mittelalters und der beginnenden Neuzeit; 1).

Bell, David, What Nuns Read: Books and Libraries in Medieval English Nunneries, Kalamazoo, Cistercian Publications, 1995. (Cistercian Studies Series; 158).

Blanton, Virginia; O’Mara, Veronica; Stoop, Patricia (eds.), Nuns'Literacies in Medieval Europe: The Hull Dialoge, Turnhout, Brepols Publishers, 2013.

Berthier, Joachim Joseph (ed.), Humbert von Romans, De eruditione Praedicatorum libri duo. Opera de vita regulari, vol. I, Roma, 1888-1889 (reimpresión 1956).

Borchling, Conrad, Literarisches und geistiges Leben im Kloster Ebstorf am Ausgange des Mittelalters, "Zeitschrift des Historischen Vereins für Niedersachsen” 4 (1905), pp. 361-407.

Carmassi, Patrizia; Schlotheuber, Eva; Breitenbach, Almut (eds.), Schriftkultur und religiöse Zentren im norddeutschen Raum Wiesbaden, Harrassowitz Verlag, 2014. (Wolfenbütteler Mittelalter-Studien; 24).

Carozzi, Claude, Humbert de Romans et la prédication, en L'ordre des Prêcheurs et son histoire en France méridionale, Toulouse, Éditions Privat, 2001, pp. 249-261. (Cahiers de Fanjeaux; 36).

Christ, Karl, Mittelalterliche Bibliotheksordnungen für Frauenklöster, "Zentralblatt für Bibliothekswesen" 59 (1942), pp. 1-29.

Costard, Monika, Spätmittelalterliche Frauenfrömmigkeit am Niederrhein. Geschichte, Spiritualität und Handschriften der Schwesternhäuser in Geldern und Sonsbeck, Tubinga, Mohr - Siebeck, 2011.

Czaja, Roman; Heimann, Heinz-Dieter; Wemhoff, Matthias (eds.), Klosterlandschaften: methodisch-exemplarische Annäherungen, München, Fink, 2008. (Mittelalter Studien des Instituts zur Interdisziplinären Erforschung des Mittelalters und seines Nachwirkens; 16).

Derolez, Albert, Les Catalogues de Bibliothèques, Turnhout, Brepols, 1979. (Typologie des sources du moyen âge occidental; 13).

Duft, Johannes, Bibliothekskataloge als Quellen der Geistesgeschichte, en Duft, Johannes (ed.), Die Abtei St. Gallen, Sigmaringen, Thorbecke, 1990, vol. I, pp. 192-202. 
Ehrenschwendtner, Marie-Luise, Die Bildung der Dominikanerinnen in Süddeutschland vom 13. bis 15. Jahrhundert, Stuttgart, Steiner, 2004. (Contubernium; 60),

Eisermann, Falk, Reseña sobre Schromm, Arnold, Die Bibliothek des ehemaligen Zisterzienserinnenklosters Kirchheim am Ries. Buchpflege und geistiges Leben in einem schwäbischen Frauenstift, "Beiträge zur Geschichte der deutschen Sprache und Literatur" 123 (2001), pp. 475-478.

Eisermann, Falk, Stimulus amoris. Inhalt, lateinische Überlieferung, deutsche Übersetzungen, Rezeption, Tubinga, Niemeyer, 2001. (Münchner Texte und Untersuchungen; 118).

Elm, Kaspar (ed.), Reformbemühungen und Observanzbestrebungen im spätmittelalterlichen Ordenswesen, Berlín, Duncker \& Humblot, 1989. (Berliner historische Studien; 14. Ordensstudien; 6).

Felten, Franz-Josef, Klosterlandschaften, en Felten, Franz-Josef; Müller, Harald; Ochs, Heidrun (eds.), Landschaft(en). Begriffe, Formen, Implikationen, Stuttgart, Steiner, 2012, pp. 157-189. (Geschichtliche Landeskunde; 68).

Fertig, Hans (ed.), Neues aus dem Literarischen Nachlasse des Humanisten Johannes Butzbach (Piemontanus), Programm des K. Neuen Gymnasiums zu Würzburg für das Studienjahr 1906-1907, Würzburg, 1907, pp. 40-57.

Friedberg, Emil (ed.), Corpus iuris canonici, vol. I, Leipzig, Bernhard Tauchnitz, 1879 (reimpresión en Leipzig de 1955).

Frings, Jutta (ed.), Krone und Schleier: Kunst aus mittelalterlichen Frauenklöstern. Katalogbuch zur Ausstellung in der Kunst- und Ausstellungshalle der Bundesrepublik Deutschland und im Ruhrlandmuseum, Múnich, Hirmer, 2005.

Gesamtkatalog der Wiegendrucke, Kommission für den Gesamtkatalog der Wiegendrucke (ed.), vol. I-VIII, primera entrega, Leipzig, Hiersemann, 1925-1940.

Gesamtkatalog der Wiegendrucke, Kommission für den Gesamtkatalog der Wiegendrucke (ed.), vol. I-VII, Stuttgart, Hiersemann, 1968.

Gesamtkatalog der Wiegendrucke, Kommission für den Gesamtkatalog der Wiegendrucke (ed.), vol. VIII-X, edición de la Deutsche Staatsbibliothek zu Berlin, Stuttgart, Hiersemann, 1978-2013.

Giermann, Renate; Härtel, Helmar (eds.), Handschriften des Klosters Ebstorf, Wiesbaden, Harrassowitz, 1994.

Griffiths, Fiona; Hotchin, Julie (eds.), Partners in Christ: Women, Men, and Religious Life in Germany, 1100-1500, Turnhout, Brepols, 2014. (Medieval Women: Texts and Contexts; 24). 
Grube, Karl (ed.), Johannes Busch, Liber de reformatione monasteriorum, Halle, Otto Hendel, 1886. (Geschichtsquellen der Provinz Sachsen und angrenzender Gebiete; 19).

Grubmüller, Klaus, Geistliche Übersetzungsliteratur im 15. Jahrhundert. Überlegungen zu ihrem literaturgeschichtlichen Ort, en Boockmann, Hartmut (ed.), Kirche und Gesellschaft im Heiligen Römischen Reich des 15. und 16. Jahrhunderts, Gotinga, Vandenhoeck und Ruprecht, 1994, pp. 59-74. (Abhandlungen der Akademie der Wissenschaften in Göttingen, Phil. Hist. K1. 3; 206)

Hamburger, Jeffrey, Nuns as Artists: The Visual Culture of a Medieval Convent, Berkeley, University of California Press, 1990.

Hamburger, Jeffrey; Jäggi, Carola; Marti, Susan; Röckelein, Hedwig (eds.), Frauen, Kloster, Kunst. Neue Forschungen zur Kulturgeschichte des Mittelalters, Turnhout, Brepols, 2007.

Hamburger, Jeffrey (ed.), Crown and Veil: Female Monasticism from the Fifth to the Fifteenth Centuries, Nueva York, Columbia University Press, 2008.

Hamburger, Jeffrey (ed.), Leaves from Paradise: the Cult of John the Evangelist at the Dominican Convent of Paradise by Soest, Cambridge, Houghton Library, 2008.

Hamburger, Jeffrey; Schlotheuber, Eva, Books in Women's Hands: Liturgy, Learning and the Libraries of Dominican Nuns in Westphalia, en Bériou, Nicole; Morard, Martin (eds.), Entre stabilité et itinérance: livres et culture des ordres mendiants (13e-15e siècles), Colloque de clôture des travaux du groupe de recherche "Les frères et les sæurs des ordres mendiants et leurs libres" (19-20 November 2010), París (en prensa).

Hamburger, Jeffrey; Schlotheuber, Eva; Marti, Susan; Fassler, Margot (eds.), Liturgical Life and Latin Learning at Paradies bei Soest, 1300-1425, Münster, Aschendorff, 2014.

Hasebrink, Burkhard, Tischlesung und Bildungskultur im Nürnberger Katharinenkloster. Ein Beitrag zu ihrer Rekonstruktion, en Kintzinger, Martin; Lorenz, Sönke; Walter, Michael (eds.), Schule und Schüler im Mittelalter. Beiträge zur europäischen Bildungsgeschichte des 9. bis 15. Jahrhunderts, Viena, Böhlau, 1999, pp. 187-216. (Beihefte zum Archiv für Kulturgeschichte; 42).

Henkel, Nikolaus; Palmer, Nigel (eds.), Latein und Volkssprache im deutschen Mittelalter 1100-1500, Regensburger Colloquium 21-24. September 1988, Tubinga, De Gruyter, 1992.

Kleinjung, Christine, Frauenklöster als Kommunikationszentren und soziale Räume: Das Beispiel Worms vom 13. bis zum Beginn des 15. Jahrhunderts, Korb, Didymos, 2008. (Studien und Texte zur Geistes- und Sozialgeschichte des Mittelalters; 1 ). 
König, Johannes (ed.), Die Chronik der Anna von Munzingen. Nach der ältesten Abschrift mit Einleitung und Beilagen. Beilage 1: Die Schriften des Johannes Meyer (edición de fragmentos), "Freiburger DiöcesanArchiv" 13 (1880), pp. 129-236.

Kruse, Britta-Juliane, Rosenkränze und Seelengärten. Bildung und Frömmigkeit in den niedersächsischen Frauenklöstern, Wolfenbüttel, Rocco, 2013.

Lehmann, Edgar, Die Bibliotheksräume der deutschen Klöster in der Zeit des Barock, Berlín, Deutscher Verlag für Kunstwissenschaft, 1918.

Lesser, Bertram, Johannes Busch: Chronist der Devotio moderna. Werkstruktur, Überlieferung und Rezeption, Fráncfort del Meno, Peter Lang, 2005. (Tradition, Reform, Innovation. Studien zur Modernität des Mittelalters; 10).

Lesser, Bertram (ed.), Johannes Busch, Liber de reformatione monasteriorum - Briefe und Predigten. Textkritische Ausgabe. Mit einer Erstedition der Schriften von Hermann Ryd, Turnhout, 2013. (Publikationen der Akademie der Augustiner-Chorherren von Windesheim), (en prensa).

Lähnemann, Henrike; Andersen, Elizabeth (eds.), A Companion to Mysticism and Devotion in the late Middle Ages, Leiden, Brill, 2014.

Lusignan, Serge, Humbert de Romans et la communication écrite au sein de l'ordre des Dominicains, en Rousselot, Lionel; Cassagnes-Brouquet, Sophie; Chauou, Amaury; Pichot, Daniel (eds.), Religion et mentalités au Moyen Âge: Mélanges en l'honneur d'Hervé Martin, Rennes, Presses Univ. de Rennes, 2003, pp. 201-209.

Makowski, Elizabeth, English Nuns and the Law in the Middle Ages: Cloistered Nuns and their Lawyers (1293-1540), Woodbridge, Boydell \& Brewer, 2012.

Martin, Therese (ed.), Reassessing the Roles of Women as Makers of Medieval Art and Architecture, vol. I y II, Leiden, Brill, 2012.

Mattern, Tanja, Liturgie im Text. Vermittlungsstrategien der Wienhäuser Messallegorese, en Dauven-van Knippenberg, Carla; Herberichs, Cornelia; Kiening, Christian (eds.), Medialität des Heils im späten Mittelalter, Zúrich, Chronos, 2009, pp. 217-239. (Medienwandel Medienwechsel - Medienwissen; 10).

Mauss, Detlev, Benedictus Füger und die Clarissen zu Runcada bei Brixen, "Gutenberg Jahrbuch" 69 (1994), pp. 292-301.

Mauss, Detlev, Benedictus Füger und die Clarissen zu Runcada bei Brixen (Fortsetzung), “Tiroler Heimat Neue Folge” 59 (1995), pp. 245-253, 292-301. 
Mecham, June, Sacred Communities, Shared Devotions. Gender, Material Culture, and Monasticism in Late Medieval Germany, Turnhout, Brepols, 2014.

Melville, Gert, 'Klosterlandschaft'. Kritische Bemerkungen zum wissenschaftlichen Wert einer Wortschöpfung, en Felten, Franz-Josef; Müller, Harald; Ochs, Heidrun (eds.), Landschaft(en). Begriffe, Formen, Implikationen, Stuttgart, Franz Steiner Verlag, 2012, pp. 195-222.

Melville, Gert; Müller, Anne (eds.), Female vita religiosa between Late Antiquity and the High Middle Ages: structures, developments and spatial contexts, Viena, Lit.-Verlag, 2011. (Vita regularis. Abhandlungen; 47).

Mengis, Simone, Schreibende Frauen um 1500. Scriptorium und Bibliothek des Dominikanerinnenklosters St. Katharina St. Gallen, Zúrich, De Gruyter, 2013. (Scrinium Friburgense; 28).

Mersch, Katharina Ulrike, Soziale Dimensionen visueller Kommunikation in hoch- und spätmittelalterlichen Frauenkommunitäten: Stifte, Chorfrauenstifte und Klöster im Vergleich, Gotinga, Vandenhoeck und Ruprecht, 2012. (Nova Mediaevalia; 10).

Mertens, Dieter, Monastische Reformbewegungen des 15. Jahrhunderts: Ideen, Ziele, Resultate, en Hlavaček, Ivan; Patschovsky, Alexander (eds.), Reform von Kirche und Reich zur Zeit der Konzilien von Konstanz (1414-1418) und Basel (1431-1449), Constanza, UvK, 1996.

Mittelalterliche Bibliothekskataloge Deutschlands und der Schweiz, Bayerische Akademie der Wissenschaften (ed.), Múnich, Beck, vol. I-4/3, 1918-2009.

Mulder-Bakker, Anneke B. (ed.), Seeing and Knowing: Women and Learning in Medieval Europe 1200-1550, Turnhout, Brepols, 2004. (Medieval Women: Texts and Contexts; 11).

Müller, Ludwig Gerhard (ed.), Der Empfänger des Weihesakraments. Quellen zur Lehre und Praxis der Kirche, nur Männern das Weihesakrament zu spenden, Würzburg, Echter, 1999.

Newman, Barbara, The Visionary Texts and Visual Worlds of Religious Women, en Hamburger, J., Crown and Veil, Nueva York, Columbia University Press, 2008, pp. 151-169.

Ochsenbein, Peter, Latein und Deutsch im Alltag oberrheinischer Dominikanerinnenklöster des Spätmittelalters, en Henkel, Nikolaus; Palmer, Nigel (eds.), Latein und Volkssprache, Tubinga, M. Niemeyer, 1992, pp. 42-51.

Otto, Henrik, Vor- und frühreformatorische Tauler-Rezeption: Annotationen in Drucken des späten 15. und frühen 16. Jahrhunderts, Gütersloh, Gütersloher Verlagshaus, 2003. (Quellen und Forschungen zur Reformationsgeschichte; 75). 
Palmer, Nigel, Daughters of Salem. The literary culture of the Cistercian nuns in South-West Germany, en Hamburger, Jeffrey F.; Jäggi, Carola; Marti, Susan; Röckelein, Hedwig, Frauen, Kloster, Kunst. Neue Forschungen zur Kulturgeschichte des Mittelalters, Turnhout, Brepols, 2007, pp. 85-100.

Palmer, Nigel, Vorwort zu: Simone Mengis, Schreibende Frauen um 1500, en Mengis, Simone, Schreibende Frauen um 1500. Scriptorium und Bibliothek des Dominikanerinnenklosters St. Katharina St. Gallen, Zúrich, De Gruyter, 2013, pp. 11-24. (Scrinium Friburgense; 28).

Ranft, Andreas; Meumann, Markus (eds.), Altes Herkommen, neue Frömmigkeit. Reform in Frauenklöstern des 15. Jahrhunderts. Sektion auf dem 44. Deutschen Kunsthistorikertag in Halle an der Saale 2002, en Traditionen - Visionen. 44. Deutscher Historikertag in Halle an der Saale 2002. Berichtsband, Múnich, Oldenbourg , 2003.

Röckelein, Hedwig, Bairische, sächsische und mainfränkische Klostergründungen im Vergleich (8. Jahrhundert bis 1100), en Schlotheuber, Eva; Flachenecker, H.; Gardill, I. (eds.), Nonnen, Kanonissen und Mystikerinnen. Religiöse Frauengemeinschaften in Süddeutschland, Gotinga, Vandenhoeck \& Riprecht, 2008, pp. 23-55. (Studien zur Germania Sacra; 31. Veröffentlichungen des Max-Planck-Instituts für Geschichte; 235).

Roest, Bert, A History of Franciscan Education (c. 1210-1517), Leiden, Brill, 2000. (Education and Society in the Middle Ages and Renaissance; 2).

Romans, Humberto de, Sermones beati Umberti Burgundi, vol. I y II, Venecia, 1603.

Romans, Humberto de, De eruditione Praedicatorum, Lib. I c. XI De persona praedicatoris, "Maxima Bibliotheca Veterum Patrum et Antiquorum Scriptorum Ecclesiasticorum" 25, Lyon, 1677.

Romans, Humberto de, Liber de instructione officialium, en Holstenius, Lucas, Codex regularum Monasticarum et Canonicarum, Augsburg, 1759 (reimpresión), vol. IV, Graz, Akad. Druck- u. Verl.-Anst., 1957, pp. 150-197.

Rüther, Andreas, Schreibbetrieb, Bücheraustausch und Briefwechsel: Der Konvent St. Katharina in St. Gallen während der Reform, en Felten, Franz-Josef; Haarländer, Stephanie; Jasper, Nikolaus (eds.), Vita religiosa im Mittelalter. FS für Kaspar Elm zum 70. Geburtstag, Berlín, Duncker \& Humblot, 1999, pp. 653-677. (Berliner historische Studien; 31. Ordensstudien; 13).

Schieffer, Rudolf, Die Entstehung der ostsächsischen Klosterlandschaft bis zum Ende des 12. Jahrhunderts, "Studien und Mitteilungen zur Geschichte des Benediktinerordens und seiner Zweige" 122 (2011), pp. 7-28. 
Schindele, Pia, Der Beitrag der Lectio Divina zur monastischen Erneuerung. Zum 500. Todestag einer Lichtenthaler Schreib- und Lesemeisterin am 20. Mai 1978, "Cistercienser Chronik" 85 (1978), pp. 13-16.

Schlotheuber, Eva, Die Franziskaner in Göttingen. Die Geschichte des Klosters und seiner Bibliothek, Werl, Dietrich-Coelde, 1996. (Saxonia Franciscana; 8).

Schlotheuber, Eva; Carmassi, Patrizia; Breitenbach, Almut (eds.), Einleitung, en Schriftkultur und religiöse Zentren im norddeutschen Raum, Wiesbaden, Harrassowitz Verlag, 2014, pp. 7-12.

Schlotheuber, Eva, Ebstorf und seine Schülerinnen in der zweiten Hälfte des 15. Jahrhunderts, en Eisermann, Falk; Schlotheuber, Eva; Honemann, Volker (eds.), Studien und Texte zur literarischen und materiellen Kultur der Frauenklöster im späten Mittelalter, Leiden, Brill, 2004, pp. 169-221. (Studies in Medieval and Reformation Thought ; 99).

Schlotheuber, Eva, Klostereintritt und Bildung. Die Lebenswelt der Nonnen im späten Mittelalter. Mit einer Edition des,Konventstagebuchs' einer Zisterzienserin von Heilig-Kreuz, bei Braunschweig (1484-1507), Tubinga, Mohr - Siebeck, 2004. (Spätmittelalter und Reformation. Neue Reihe; 24)

Schlotheuber, Eva, Humanistisches Wissen und geistliches Leben. Caritas Pirckheimer und die Geschichtsschreibung im Nürnberger Klarissenkonvent, "Die Pirckheimer. Humanismus in einer Nürnberger Patrizierfamilie -Pirckheimer Jahrbuch" 21 (2005), pp. 89-118.

Schlotheuber, Eva; Gardill, Ingrid; Flachenecker, Helmut (eds.), Nonnen, Kanonissen und Mystikerinnen. Religiöse Frauengemeinschaften in Süddeutschland, Gotinga, 2008. (Studien zur Germania Sacra; 31. Veröffentlichungen des Max-Planck-Instituts für Geschichte; 235).

Schlotheuber, Eva, Per vim et metum - Die bitteren Klagen der Mädchen und Frauen an der römischen Kurie über ein erzwungenes Professgelïbde, en Meyer, Andreas (ed.), Kirchlicher und religiöser Alltag im Spätmittelalter, Akten der internationalen Tagung in Weingarten 4.7. Oktober 2007, Ostfildern, Thorbecke, 2010, pp. 165-176. (Schriften zur südwestdeutschen Landeskunde; 69).

Schmid, Barbara, Schreiben für Status und Herrschaft. Deutsche Autobiographik in Spätmittelalter und früher Neuzeit, Zúrich, Chronos, 2006, pp. 59-114.

Schromm, Arnold, Die Bibliothek des ehemaligen Zisterzienserinnenklosters Kirchheim am Ries. Buchpflege und geistiges Leben in einem schwäbischen Frauenstift, Tubinga, Niemeyer, 1998. (Studia Augustana; 9). 
Signori, Gabriela, Berühmte Frauen oder gelehrte Jungfrauen? Frühhumanistische Frauenapologien zwischen Kloster und Welt, en Altenberend, Johannes (ed.), Kloster - Stadt - Region. Festschrift für Heinrich Rüthing mit einem Geleitwort von Reinhart Koselleck, Bielefeld, Verlag für Regionalgeschichte, 2002, pp. 27-44.

Simon, André, L'Ordre des Pénitentes de Sainte Marie-Madeleine en Allemagne au XIIIme siècle, Friburgo, Saint-Paul, 1918.

Smolinsky, Heribert, Kirchenreform als Bildungsreform im Spätmittelalter und in der frühen Neuzeit, en Dickerhof, Harald (ed.), Bildungsund schulgeschichtliche Studien zu Spätmittelalter, Reformation und konfessionellem Zeitalter, Wiesbaden, Dr. Ludwig Reichert Verlag, 1994. (Wissensliteratur im Mittelalter; 19).

Stamm, Gerhard, Klosterreform und Buchproduktion. Das Werk der Schreibund Lesemeisterin Regula, en Siebenmorgen, Harald (ed.), 750 Jahre Zisterzienserinnen-Abtei Lichtenthal, Sigmaringen, Thorbeke, 1995, pp. 63-71.

Thali, Johanna, Qui vult cum Deo semper esse, frequenter debet orare, frequenter et legere. Formen und Funktionen des Lesens in der klösterlichen Frömmigkeitskultur, en Lutz, Eckart Conrad; Backes, Martina; Matter, Stefan (eds.), Lesevorgänge: Prozesse des Erkennens in mittelalterlichen Texten, Bildern und Handschriften, Zúrich, Chronos, pp. 421-458.

Thoma, Gertrud, Ökonomie und Verwaltung in mittelalterlichen Frauenkonventen Süddeutschlands, en Schlotheuber, Eva; Flachenecker, Helmut; Gardill, Ingrid (eds.), Nonnen, Kanonissen und Mystikerinnen. Religiöse Frauengemeinschaften in Süddeutschland, Gotinga, 2008, pp. 297-313. (Studien zur Germania Sacra; 31. Veröffentlichungen des Max-Planck-Instituts für Geschichte; 235).

Vosding, Lena (ed.), Schreib die Reformation von Munchen gancz daher. Teiledition und historische Einordnung der Nürnberger Klarissenchronik (um 1500), Núremberg, Stadtarchiv Nürnberg, 2012. (Quellen und Forschungen zur Geschichte und Kultur der Stadt Nürnberg; 37).

Williams-Krapp, Werner, Die Bedeutung der reformierten Klöster des Predigerordens für das literarische Leben in Nürnberg im 15. Jahrhundert, en Williams-Krapp, Werner (ed.), Geistliche Literatur des späten Mittelalters. Kleine Schriften, Tubinga, Mohr - Siebeck, 2013, pp. 189-205. (Spätmittelalter, Humanismus, Reformation; 64).

Williams-Krapp, Werner, Frauenmystik und Ordensreform, en Williams-Krapp, Werner (ed.), Geistliche Literatur des späten Mittelalters. Kleine Schriften, Tubinga, Mohr - Siebeck, 2013, pp. 159-172. (Spätmittelalter, Humanismus, Reformation; 64). 
Williams-Krapp, Werner, Observanzbewegungen, monastische Spiritualität und geistliche Literatur im 15. Jahrhundert, en Williams-Krapp, Werner (ed.), Geistliche Literatur des späten Mittelalters. Kleine Schriften, Tubinga, Mohr - Siebeck, 2013, pp. 173-188. (Spätmittelalter, Humanismus, Reformation; 64).

Willing, Antje, Die Bibliothek des Klosters St. Katharina zu Nürnberg. Synoptische Darstellung der Bücherverzeichnisse, vols. I y II, Berlín, Akademie Verlag, 2012.

Fecha de recepción del artículo: noviembre 2013

Fecha de aceptación y versión final: febrero 2014 